\title{
The Autophagy Receptor TAX1BP1 (T6BP) is a novel player in antigen presentation by MHC-II molecules.
}

Mathias Pereira ${ }^{1,2, *}$, Clémence Richetta ${ }^{2, *}$, Gabriela Sarango ${ }^{1,2, *}$, Anita Kumari ${ }^{1,2}$, Michael Ghosh $^{3}$, Lisa Bertrand ${ }^{1,2}$, Cédric Pionneau ${ }^{4}$, Morgane Le Gall ${ }^{5}$, Sylvie Grégoire ${ }^{1,2}$, Raphaël Jeger-Madiot $^{2}$, Elina Rosoy ${ }^{2}$, Mathias Faure ${ }^{6,7}$, Audrey Esclatine ${ }^{1}$, Stéphanie Graff-Dubois ${ }^{2}$, Stefan Stefanović ${ }^{3}$, Bénédicte Manoury ${ }^{8}$, Bertha Cecilia Ramirez ${ }^{1,2}$ and Arnaud Moris ${ }^{1,2}$.

${ }^{1}$ Université Paris-Saclay, CEA, CNRS, Institute for Integrative Biology of the Cell (I2BC), 91198, Gif-sur-Yvette, France.

${ }^{2}$ Sorbonne Université, INSERM, CNRS, Center for Immunology and Microbial Infections (CIMI-Paris), 75013, Paris, France.

${ }^{3}$ Department of Immunology, Institute for Cell Biology, University of Tübingen, 72076, Tübingen, Germany.

${ }^{4}$ Sorbonne Université, INSERM, UMS PASS, Plateforme Post-génomique de la Pitié Salpêtrière (P3S), 75013, Paris, France.

5 3P5 proteom'IC facility, Université de Paris, Institut Cochin, INSERM U1016, CNRS-UMR 8104, 75014, Paris, France.

${ }^{6}$ CIRI, Centre International de Recherche en Infectiologie, Université de Lyon, Inserm U1111, Université Claude Bernard Lyon 1, CNRS, UMR5308, ENS de Lyon, F-69007, Lyon, France.

${ }^{7}$ Equipe Labellisée par la Fondation pour la Recherche Médicale, FRM

${ }^{8}$ Institut Necker Enfants Malades, INSERM U1151-CNRS UMR 8253, Faculté de médecine Necker, Université de Paris, 75015, Paris, France.

* These authors contributed equally to this work.

To whom correspondence should be addressed:

Arnaud Moris

Institute for Integrative Biology of the Cell

UMR 9198 CNRS, CEA, Université Paris-Saclay

Avenue de la Terrasse, 91190 Gif-sur-Yvette Cedex, France

Email: arnaud.moris@i2bc.paris-saclay.fr

\section{Present address:}

CR: LBPA, ENS-Paris Saclay, CNRS UMR8113, Université Paris Saclay, Gif-sur-Yvette, France.

SGD and RJM: Sorbonne Université, INSERM U959, Immunology-ImmunopathologyImmunotherapy (i3), Paris, France.

\section{Running Title:}

TAX1BP1 in MHC-II-restricted antigen presentation. 


\begin{abstract}
$\mathrm{CD}^{+} \mathrm{T}$ lymphocytes play a major role in the establishment and maintenance of immunity. They are activated by antigenic peptides derived from extracellular or newly synthesized (endogenous) proteins presented on the surface of antigen presenting cells (APCs) by the MHC-II molecules. The pathways leading to endogenous MHC-II presentation remain poorly characterized. We demonstrate here that the autophagy receptor, T6BP, influences both autophagy-dependent and -independent endogenous presentation of HIV- and HCMV-derived peptides. By studying the immunopeptidome of MHC-II molecules, we show that T6BP affects both the quantity and quality of peptides presented. T6BP silencing induces mislocalization of the MHC-II-loading compartments and a rapid degradation of the invariant chain (CD74) without altering the expression and internalization kinetics of MHC-II molecules. We determined the interactome of T6BP in model APC and identified calnexin as a T6BP partner. Remarkably, calnexin silencing replicates the functional consequences of T6BP silencing: decreased $\mathrm{CD}^{+} \mathrm{T}$ cell activation and exacerbated CD74 degradation. Altogether, we unravel T6BP as a key player of the MHC-II-restricted endogenous presentation pathway and we propose one potential mechanism of action.
\end{abstract}

\title{
Key Words:
}

Calnexin/ $\mathrm{CD}^{+} \mathrm{T}$ cell activation/ Interactome/ Immunopeptidome/ Virus 


\section{Introduction}

$\mathrm{CD}^{+}$helper $\mathrm{T}$ cells that orchestrate adaptive immune responses recognize pathogen- or tumour-derived peptides presented by the major histocompatibility complex class-II (MHCII) molecules. MHC-II molecules are expressed by professional antigen-presenting cells (APC) such as B cells, macrophages and dendritic cells (DC), thymic epithelial cells (TEC), and by non-professional APCs in inflammatory conditions (Roche \& Furuta, 2015; Wijdeven et al, 2018). The MHC-II transactivator, CIITA, governs the transcription of the MHC-II locus that includes genes encoding for the $\alpha$ - and $\beta$-chains of MHC-II molecules, the invariant chain Ii (CD74) and the chaperon proteins HLA-DM/HLA-DO (Reith et al, 2005). The transmembrane $\alpha$ - and $\beta$-chains are assembled within the endoplasmic reticulum (ER), where they associate with CD74 leading to the formation of nonameric $\alpha \beta-C D 74$ complexes that traffic into late endo-lysosomal compartments named MIIC (Bakke \& Dobberstein, 1990; Lotteau et al, 1990; Neefjes et al, 1990; Roche et al, 1991). In the MIIC, CD74 is progressively cleaved by vesicular proteases (Manoury et al, 2003; Nakagawa et al, 1998; Riese et al, 1996; Shi et al, 2000), leaving a residual MHC-II-associated Ii peptide (CLIP) that occupies the peptide binding groove (Bijlmakers et al, 1994; Busch et al, 1996; Roche \& Cresswell, 1991). HLA-DM then facilitates the exchange of the CLIP fragments with high affinity peptides that are generated from pathogen- or tumor-derived antigens (Denzin \& Cresswell, 1995; Morris et al, 1994; Sanderson et al, 1994). MHC-II molecules are then transported to the plasma membrane to expose antigenic peptides to $\mathrm{CD} 4{ }^{+} \mathrm{T}$ cells (Thibodeau et al, 2019).

MHC-II molecules present peptides derived from extra- and intra-cellular sources of antigens, so-called exogenous and endogenous presentation, respectively (Veerappan Ganesan \& Eisenlohr, 2017; Watts, 2004). Extracellular antigens are captured and internalized into APCs by various means including macropinocytosis, phagocytosis or receptor-mediated endocytosis (Roche \& Furuta, 2015). Antigens are then delivered to the MIIC where they are progressively degraded by endo-lysosomal proteases such as cathepsins (Watts, 2004), into peptides (or epitopes) ranging from 12 to 25 amino acids in length, that can be loaded on nascent MHC-II molecules (Rudensky et al, 1991; Unanue et al, 2016). Epitopes from extracellular antigens can also bind, in early endosomes, on recycling MHC-II molecules (Pinet et al, 1995; Sinnathamby \& Eisenlohr, 2003). The endogenous pathway relies on protein antigen synthesis by virus-infected (Eisenlohr \& Hackett, 1989; Jacobson et al, 1988; Jaraquemada et al, 1990; Nuchtern et al, 1990; Sekaly et al, 1988; Thiele et al, 2015) or tumor cells (Tsuji et al, 2012). Some early in vitro studies showed that neosynthesized selfepitopes are displayed, after lysosomal proteolysis, by MHC-II molecules leading to CD4 ${ }^{+} \mathrm{T}$ cell activation (Bikoff \& Birshtein, 1986; Rudensky \& Yurin, 1989; Weiss \& Bogen, 1989). More recently, it was shown that the initiation of $\mathrm{CD}^{+} \mathrm{T}$ cell responses to influenza virus is mainly driven by epitopes derived from the processing of intracellular antigens within APCs (Miller et al, 2015). However, the pathways leading to the loading of MHC-II molecules by endogenous antigens remain poorly characterized. Components of the MHC class-I (MHC-I) processing pathway such as proteasomes have been implicated (Lich et al, 2000; Tewari et al, 2005). One unresolved issue is how cytosolic antigens are transported in MHC-II-enriched compartments (Crotzer \& Blum, 2008; Dani et al, 2004). For some specific epitopes but not others, the transporter associated with antigen presentation of MHC-I molecules (TAP) has 
been associated to the delivery of endogenous peptide on MHC-II molecules (Malnati et al, 1992; Tewari et al., 2005). In fact, depending on the cellular localization, the trafficking and the nature of the antigen itself, different pathways might be involved in the degradation and delivery of endogenous antigens to MHC-II loading compartments (Leung, 2015; Mukherjee et al, 2001; Tewari et al., 2005).

The pathways of autophagy contribute to the processing of MHC-II-restricted endogenous antigens. The receptor of chaperone-mediated autophagy, LAMP-2A, has been shown to facilitate the presentation of a cytosolic self-antigen by MHC-II molecules (Zhou et al, 2005). The analysis of the MHC-II immunopeptidome revealed that macroautophagy (herein referred to as autophagy) also contributes to the processing of cytoplasmic and nuclear antigens (Dengjel et al, 2005). Autophagy is a self-eating cellular degradation pathway, in which double-membrane autophagosomes deliver their cytoplasmic constituents for lysosomal degradation (Kirkin, 2020). Using various models, several labs established that autophagy participates, in thymic epithelial cells (TEC), in the generation of MHC-II-restricted endogenous epitopes and strongly influences thymic selection of auto-reactive $\mathrm{CD}^{+}{ }^{+} \mathrm{T}$ cells (Aichinger et al, 2013; Schuster et al, 2015). Other evidence that autophagy plays a role in endogenous antigen presentation comes from in-vitro studies using APCs transfected with mRNA encoding tumor antigens (Dorfel et al, 2005) or cDNA encoding tumor or viral antigens targeted to autophagosomes (Coulon et al, 2016; Fonteneau et al, 2016; Jin et al, 2014; Schmid et al, 2007). Targeting antigens to autophagosomes through the fusion to LC3, an autophagy effector that incorporates into and participates in the elongation of autophagosomes, enhances the capacity of APCs to activate antigen-specific $\mathrm{CD}^{+}{ }^{+} \mathrm{T}$ cells (Coulon et al., 2016). However, overall, there are a limited numbers of examples where endogenous degradation of native tumor or viral antigens has been shown to be dependent on autophagy (Leung, 2015; Paludan et al, 2005). In fact, autophagy effectors may directly or indirectly affect the presentation of MHC-II-restricted antigens by regulating, for instance, the delivery of proteases into the MIIC (Lee et al, 2010). Thereafter, autophagy also contributes to exogenous presentation of viral and bacterial antigens (Blanchet et al, 2010; Jagannath et al, 2009). The molecular links between autophagy and MHC-II-restricted antigen presentation, in particular the mechanisms allowing the delivery of autophagy-degraded antigens to the MIIC, are poorly defined.

A growing body of evidence indicates that autophagosomes selectively target their cargos, while excluding the rest of the cytoplasmic content (Kirkin, 2020). Several forms of selective autophagy exist, depending on the substrate, but all rely on the so-called autophagy receptors (ARs) that include: Nuclear Dot Protein 52 (NDP52), Optineurin (OPTN), Sequestosome-1 / p62, Next to BRCA1 gene protein-1 (NBR1) and TAX1-Binding Protein-1 also called TRAF6-Binding Protein (TAX1BP1/T6BP) (Kirkin \& Rogov, 2019). ARs contain ubiquitin $(\mathrm{Ub})$ and LC3-binding domains that allow on the one hand, binding to ubiquitinated proteins and on the other hand, their targeting into autophagosomes, through interaction with LC3 on the internal membranes of forming autophagosomes (Kirkin \& Rogov, 2019). As such, ARs are involved in multiple cellular processes including selective degradation of incoming bacteria and of damaged mitochondria, processes called xenophagy (Tumbarello et al, 2015) and mitophagy (Randow \& Youle, 2014), respectively. In addition to their role in selective autophagy, T6BP, NDP52 and OPTN are required for the maturation of autophagosomes 
(Tumbarello et al, 2012). Thanks to the binding to myosin-VI, these ARs bridge autophagosomes to Tom-1-expressing endosomes and lysosomes, thus facilitating their fusion (Morriswood et al, 2007; Sahlender et al, 2005; Tumbarello et al., 2012). T6BP, OPTN, and NDP52 by promoting autophagosome maturation (Verlhac et al, 2015), are essential for the degradation of Salmonella typhimurium (Lin et al, 2019; Thurston et al, 2009; Wild et al, 2011). Remarkably, T6BP, NDP52, and p62 were also shown to orchestrate the maturation of early endosomes into late endosomes (Jongsma et al, 2016). This process also involves the Ub-binding domain of these receptors (Jongsma et al., 2016). Therefore, ARs exert multiple redundant but also exclusive roles in selective autophagy, and in the traffic and maturation of vesicles such as autophagosomes and endosomes.

Here, we hypothesize that ARs may contribute at various, so far unknown, levels to MHC-IIrestricted viral antigen presentation. We show that silencing of NDP52, OPTN and p62 in model APCs does not significantly affect the presentation of an autophagy-dependent antigen to $\mathrm{CD}^{+} \mathrm{T}$ cells. In contrast, T6BP influences both autophagy-dependent and -independent endogenous viral, as well as cellular, antigen processing and presentation by MHC-II molecules. In fact, the action of T6BP is not limited to viral antigens, as the global repertoire of peptides presented by MHC-II molecules (immunopeptidome) is dramatically changed upon T6BP silencing. We show that T6BP silencing does not perturb the global cell-surface expression nor internalization kinetics of MHC-II molecules. However, it induces a significant relocalization of the MIIC closer to the nucleus. Importantly, we demonstrate that the absence of T6BP expression induces a strong and rapid degradation of the invariant chain CD74, which directly influences the quality of the peptide repertoire loaded on MHC-II molecules. Finally, to get a hint on possible mechanisms, we defined the interactome of T6BP and identify novel protein partners that potentially participate to the T6BP-mediated regulation of MHC-II peptide loading. Among them, we identified the ER chaperone calnexin whose silencing also decreases the capacity of model APCs to activate $\mathrm{CD}^{+} \mathrm{T}$ cells. Altogether, this study unravels a new role for T6BP as a key player in MHC-II-restricted antigen presentation, and in $\mathrm{CD} 4^{+} \mathrm{T}$ cell immunity. 


\section{Results}

\section{T6BP silencing influences endogenous viral antigen presentation and $\mathrm{CD}^{+} \mathrm{T}$ cell} activation.

Owing to their functions in selective autophagy as well as in the maturation of autophagosomes, we focused our work on NDP52, OPTN, and T6BP asking whether these ARs might be involved in endogenous antigen presentation by MHC-II molecules and subsequent activation of $\mathrm{CD}^{+} \mathrm{T}$ cells. To this end, HeLa cells modified to express CIITA (HeLa-CIITA) were silenced for the expression of ARs using siRNAs targeting NDP52, OPTN and T6BP and evaluated for their capacity to activate CD4 T cell clones (Fig 1A). An siRNA targeting p62 was also included as this AR plays, in multiple models, a dominant role in selective autophagy but does not participate in the maturation of autophagosomes (Tumbarello et al., 2012). 24h post-siRNA transfection HeLa-CIITA cells were transfected with a plasmid encoding HIV-Gag protein fused to LC3. This Gag-LC3 fusion enables a specific targeting of Gag into autophagosomes and enhances HIV-specific T cell activation in an autophagy-dependent manner (Coulon et al., 2016). 48h post-siRNA treatment (24h post DNA transfection), we analysed by flow cytometry the percentages of living and of Gagpositive $\left(\mathrm{Gag}^{+}\right)$cells, using viability dye and Gag intracellular staining, respectively (Fig S1A). In all tested conditions, the levels of $\mathrm{Gag}^{+}$cells were similar and the sequential transfections (siRNA and cDNA) had no significant influence on cell viability (Fig S1B). The silencing of AR expression was also analysed by Western Blot. As compared to the control siRNA (CTRL), all siRNAs led to a marked decrease of AR expressions (Fig 1C). HeLaCIITA cells were then co-cultured with Gag-specific $\mathrm{CD}^{+} \mathrm{T}$ cells that we previously isolated and characterized (Moris et al, 2006). These Gag-specific CD4 ${ }^{+} \mathrm{T}$ cell clones recognize HIVinfected cells (Coulon et al., 2016; Moris et al., 2006). CD4+ T cell activation was monitored using IFN- $\gamma$-ELISPOT (Fig 1B). Cells transfected with CTRL, NDP52, OPTN, or p62 targeting siRNA led to similar levels of CD4+ T cell activation (Fig 1B, right and left panel). In contrast, T6BP silencing greatly decreased the activation of Gag-specific T cells (Fig 1B, left panel). On average, T6BP silencing led to a $75 \%$ decrease of Gag-specific $\mathrm{CD}^{+}{ }^{+} \mathrm{T}$ cell activation (Fig 1B, right panel).

We next analysed the effect of T6BP silencing on autophagy-independent endogenous viral antigen processing by MHC-II molecules. As previously, HeLa-CIITA cells were first transfected with CTRL- or T6BP-silencing siRNAs (siCTRL and siT6BP respectively), then transfected with various plasmids encoding Gag, Gag-LC $3_{\mathrm{G} 120 \mathrm{~A}}$ or Gag-LC3, and co-cultured with the Gag-specific CD4 ${ }^{+}$T cells (Fig 1D). We have previously shown that the MHC-IIrestricted presentation of neosynthesized (endogenous) Gag antigen does not rely on autophagy degradation (Coulon et al., 2016). Gag-LC3 $3_{\mathrm{G} 120 \mathrm{~A}}$ was used as negative control for autophagy dependent degradation, as the G120A mutation in the C-terminus of LC3 abolishes the lipidation and incorporation of LC3 in the nascent membranes of autophagosomes, thus preventing Gag targeting into autophagosomes (Coulon et al., 2016). 24h-post transfection and prior co-culture with the $\mathrm{CD}^{+} \mathrm{T}$ cells, the percentage of $\mathrm{Gag}^{+}$cells and Gag expression levels and the cell viability were similar in all tested conditions (Fig S1C). As previously, T6BP silencing strongly decreased the capacity of HeLa-CIITA cells expressing Gag-LC3 to activate the Gag-specific T cells (Fig 1D, left panel). However, we observed that the effect of 
T6BP silencing was not limited to Gag-LC3 as the capacity of HeLa-CIITA expressing Gagor Gag-LC3 $3_{\mathrm{G} 120 \mathrm{~A}}$ to activate the $\mathrm{CD} 4^{+} \mathrm{T}$ cell clones, was also reduced in siT6BP-treated cells (Fig 1D, left panel). Importantly, T6BP silencing did not interfere with the ability of HeLaCIITA cells to present the cognate peptide recognized by Gag-specific T cells when the peptide was added exogenously (Fig 1D, right panel). These results suggest that T6BP silencing influences the generation of Gag-, Gag-LC3- and Gag-LC3 $3_{\mathrm{G} 120 \mathrm{~A}}$-derived endogenous epitopes and their subsequent presentation by MHC-II molecules to Gag-specific $\mathrm{CD}^{+} \mathrm{T}$ cells but does not affect the presentation of exogenous peptides by MHC-II molecules. Note that we obtained similar results with several siRNAs targeting different exons of T6BP mRNA, and using intracellular cytokine staining to monitor Gag-specific $\mathrm{CD}^{+} \mathrm{T}$ cell activation (data not shown). We then sought to extend these observations to additional viral antigens. To this end, HeLa-CIITA cells treated with siCTRL or siT6BP were transfected with a plasmid encoding the immunodominant pp65 HCMV antigen, and cocultured with a pp65-specific $\mathrm{CD}^{+} \mathrm{T}$ cell line (Fig 1E). The viability and the percentage of pp $65^{+}$HeLa-CIITA cells were similar in both conditions (not shown). Remarkably, T6BP silencing also led to a strong reduction of $\mathrm{CD}^{+} \mathrm{T}$ cell activation (Fig 1E, left panel). As previously, the capacity of HeLa-CIITA cells to present the cognate pp65-derived peptide, added exogenously, was not affected (Fig 1E, right panel). These results demonstrate that regardless of the antigen tested, T6BP silencing dramatically influences the capacity of APCs to activate antigen-specific $\mathrm{CD}^{+}{ }^{+} \mathrm{T}$ cells. The effect of T6BP silencing is broader than we initially anticipated as it impacts both autophagy-dependent and -independent endogenous viral antigen processing and presentation by MHC-II molecules.

\section{T6BP silencing dramatically alters the immunopeptidome of MHC-II molecules.}

To study whether the action of T6BP on MHC-II-restricted antigen presentation might affect a broader range of potential antigens, we analysed the effect of T6BP silencing on the global peptide repertoire (immunopeptidome) presented by MHC-II molecules. To this end, HeLaCIITA cells were either Mock-treated or transfected with CTRL or T6BP-silencing siRNA, MHC-II molecules were immunoprecipitated by using the TÜ39 antibody (specific to HLADP, DQ, and DR), and finally the peptide-ligands were identified using mass-spectrometry (LC-MS/MS). To assess the intrinsic variability of the MHC-II ligandome, we analysed simultaneously the ligandome of two samples from mock treated HeLa-CIITA cells that were split $48 \mathrm{~h}$ prior to lysis and MHC-II immunoprecipitations (IP). In these settings, 57\% of identified peptides were shared by the two samples of mock-treated cells (Fig 2A, left panel). Two biological replicates of siRNA treated cells were analysed, one is presented in Fig 2. We observed that 1349 peptides (representing $25 \%$ of the peptides) were presented by MHC-II molecules exclusively in HeLa-CIITA cells expressing T6BP (Fig 2A, right panel, siCTRL). Remarkably, in the absence of T6BP expression, 2198 new MHC-II ligands (40\% of the peptides) were identified (Fig 2A, right panel, siT6BP). Overall, only $35 \%$ of the peptides (1914 peptides) were shared between control and the T6BP-silenced conditions (Fig 2A, right panel). Together these results show that, although the immunopeptidome varies between two identical cell cultures, the absence of T6BP has a pronounced and dramatic influence on the repertoire of peptides presented by MHC-II molecules. 
We then sought to analyse the influence of T6BP on the relative abundance and the quality, meaning the affinity to MHC-II molecules, of peptides presented. However, peptides eluted from MHC-II molecules are variable in length and one core epitope required for MHC-II binding, usually 13 amino acid long, can be found in multiple peptides with $\mathrm{N}$ - and $\mathrm{C}$ terminal extensions (Rammensee et al, 1999). To circumvent this limitation, we adapted a protocol, published by Alvaro-Benito et al., to identify the core epitopes within our data sets using the Peptide Lansdscape Antigenic Epitope Alignment Utility (PLAtEAU) algorithm (Alvaro-Benito et al, 2018). A total of 864 and 1245 unique core epitopes were identified in the groups Mock1/Mock2 and siCTRL/siT6BP, respectively. PLAtEAU also allows the calculation of the relative abundance of the core epitopes based on the LC-MS/MS intensities of peptides containing the same core epitope. Between the two mock-treated samples around $5 \%$ of the core epitopes showed a significant difference in their relative abundances (Fig 2B, left panel). Remarkably, between the siCTRL and siT6BP conditions, 55\% of the core epitopes displayed a relative abundance that was significantly different between siCTRL and siT6BP conditions, with 436 and 246 epitopes more abundant in the siT6BP or siCTRLtreated cells, respectively, among 1245 peptides (Fig 2B, right panel). Therefore, T6BP silencing influences both the repertoire of peptides (Fig 2A) and the relative abundance of a majority of the core epitopes presented by MHC-II molecules (Fig 2B).

Having identified the core epitopes, using NetMHCIIpan4.0 algorithm (Reynisson et al, 2020), we next analysed the relative binding affinities of the exclusive peptides, identified in siCTRL and siT6BP conditions, to the HLA-DR $\beta 1 * 0102$ allele that is expressed by HeLaCIITA cells. Strikingly, when T6BP is expressed (siCTRL), more than $90 \%$ of the epitopes were predicted to be HLA-DR $\beta 1 * 0102$ binders $(26 \%$ and $65 \%$, strong and weak binders, respectively). In contrast, in T6BP-silenced cells, below $50 \%$ of peptides were predicted to bind HLA-DR $\beta 1 * 0102$ (16\% and 33\%, strong and weak binders respectively). We also compared the predicted binding capacities of core epitopes exclusive to the Mock1 or Mock2 conditions and it did not reveal a significant difference in terms relative affinity (not shown). Together, these results suggest that in the absence of T6BP, the peptide repertoire presented by HLA-DR $\beta 1 * 0102$ molecules has a predicted weaker relative affinity.

Note that we also analysed on the same samples whether T6BP might influence the immunopeptidome of MHC-I molecules. Cells transfected with siCTRL or siT6BP and the two mock-treated samples were submitted to IP but using the pan anti-MHC-I antibody, W632, and the peptide ligands sequenced using LC-MS/MS. We did not observe a significant influence of T6BP on the percentage of shared or exclusive peptides comparing the two mock-treated samples and the siCTRL/siT6BP conditions (Fig S2A). We further analysed the relative affinities of the exclusive peptides bound to siCTRL- and to siT6BP-treated cells. In contrast, to MHC-II ligands, MHC-I molecules present short 9-mer peptides that correspond to the core epitope (Rammensee et al., 1999). We thus directly analysed the relative affinities using the NetMHCpan 4.0 algorithm (Jurtz et al, 2017). The percentage of strong, weak and non-binder peptides were similar in the control and T6BP-silenced cells (Fig S2B). Therefore, the action of T6BP seems to be limited to the MHC-II-restricted antigen presentation pathway. T6BP expression has a strong influence on the peptide repertoire, the relative abundance and the relative affinity of epitopes presented by MHC-II molecules. 


\section{T6BP silencing does not significantly influence the cell-surface expression levels and the internalization kinetics of MHC-II molecules.}

Although T6BP silencing does not significantly alter the capacity of cells loaded with exogenous peptides to activate antigen-specific $\mathrm{CD}^{+} \mathrm{T}$ cells (Fig 1D and E right panels), we asked whether T6BP might influence the internalisation of MHC-II molecules. Using flow cytometry, we first monitored on T6BP-silenced HeLa-CIITA cells, the expression levels of mature and of mature/immature HLA-DR molecules using the L243 and TÜ36 antibodies, respectively (Fig 3A, left panel: L243 and right panel: TÜ36). Using both antibodies, we noticed a slight increase of HLA-DR cell-surface expression levels on cells silenced for T6BP expression (Fig 3A). We next analysed the effect of T6BP silencing on the internalization kinetics of MHC-II molecules. HeLa-CIITA cells treated with siCTRL or siT6BP were coated at $4{ }^{\circ} \mathrm{C}$ for 30 min with the anti HLA-DR L243 antibody. The L243 antibody has been shown to act as an agonist of MHC-II molecules leading to their cellular internalization (De Gassart et al, 2008). The cells were then maintained at $4^{\circ} \mathrm{C}$ to monitor the antibody drop-off (Fig 3C) or incubated at $37^{\circ} \mathrm{C}$ to follow internalization of MHC-II molecules (Fig 3B). The cells were collected at the indicated time points and stained at $4^{\circ} \mathrm{C}$ with a labelled secondary antibody to detect the remaining $\mathrm{L} 243$ antibody conjugated with MHC-II molecules at the cell surface (Fig 3B and C). At $4^{\circ} \mathrm{C}$, the mean fluorescent intensity (MFI) of HLA-DR molecules remained stable (Fig 3C). In contrast, at $37^{\circ} \mathrm{C}$, the MFI dropped reaching a plateau after $40 \mathrm{~min}$ in both experimental conditions (Fig 3B, left panel), thus suggesting that the L243 antibody induced the internalization of HLA-DR molecules in the presence or absence of T6BP expression. As previously, compared to control condition, the silencing of T6BP increased slightly the expression levels (MFI) of HLA-DR molecules on the cell surface. However, it did not influence the kinetics of internalization of HLA-DR (Fig 3B, right panel). Although strongly influencing antigen-presentation of viral antigens and the immunopeptidome of MHC-II molecules, T6BP silencing does not significantly influence internalization of MHC-II molecules.

\section{T6BP silencing affects the cellular localization of the MIIC.}

We then asked whether T6BP might play a role in the intracellular trafficking of MHC-II molecules, before mature peptide-loaded MHC-II molecules reach the plasma membrane. To this end, using confocal microscopy analysis, we evaluated in HeLa-CIITA cells the effect of T6BP silencing on endo-lysosomal compartments. We first confirmed previous results (Petkova et al, 2017) showing that T6BP silencing leads to the accumulation of LC3-positive puncta corresponding to autophagosomes (Fig S3A-B). Note that at steady state in HeLaCIITA-cells, T6BP did not co-localize with $\mathrm{LC}^{+}$puncta (Fig S3B). We extended this observation using electron microscope analysis of the morphology of siRNA-treated cells and confirmed that large (around $1 \mu \mathrm{m}$ in length) vesicles with double membrane (with 20 to 30 $\mathrm{nm}$ interspace) accumulated in about $80 \%$ of the cells silenced for T6BP expression (Fig $\mathrm{S} 3 \mathrm{E}$ ). These structures where not observed in the siCTRL-treated cells. Two independent experiments were performed and at least 40 cells for each treatment were analysed. We then analysed by confocal microscopy the subcellular localization of MHC-II molecules together with markers of autophagosomes, late endosomes and lysosomes. In HeLa-CIITA cells (Bania et al, 2003), MHC-II molecules, stained with an antibody to mature HLA-DR 
molecules (L243), localized in patches corresponding to intracellular vesicles that did not include T6BP (Fig 4A). Whatever the siRNA treatment, MHC-II molecules did not colocalize with LC3-positive puncta (Fig S3C and D). However, upon T6BP silencing, compared to the control condition, MHC-II molecules seemed localized closer to the nucleus (Fig 4A). We determined the average distance to the nucleus and the number of vesicles in more than 150 cells representing over $20000 \mathrm{MHC}^{+}$puncta (Fig 4B). We noticed a slight but significant decrease of MHC-II-positive vesicle distance to the nucleus upon T6BP silencing (Fig 4B). The numbers of MHC-II ${ }^{+}$spots per cell were not significantly different (Fig 4B). Using an anti-LAMP1 antibody, we then analysed effect of T6BP expression on late endolysosomal compartments. As compared to control cells, in T6BP-silenced cells, we observed a significant re-localization of LAMP-1-positive vesicles at the proximity of the nucleus (Fig 4C and D). The number of LAMP-1-positive vesicles was globally unchanged (Fig 4C and D). We next asked whether the MIIC itself might be affected by T6BP silencing in HeLaCIITA cells. The MIIC is a labile ill-defined acidified compartment that has been shown to be positive for multiple markers that do not always overlap (Roche \& Furuta, 2015). We used Lysotracker that stains acidified compartments, CD63, a tetraspanin molecule anchored to the membrane of the intraluminal vesicles of the MIIC (Roche \& Furuta, 2015), HLA-DM, the chaperone involved in MHC-II peptide loading, and MHC-II molecule stainings to identify the MIIC. In the absence of T6BP, we observed a pronounced, statistically significant, relocalization of Lysotracker-positive vesicles close to the nuclei but the number of Lysotracker-positive vesicles was unchanged (Fig 4E and F). Remarkably, in siT6BP-treated cells, Lysotracker-positive vesicles showed increased co-localization with MHC-II molecules (Fig 4E and F). Upon T6BP silencing, CD63-positive vesicles were also strongly re-localized around the nucleus and showed an increased co-localization with MHC-II-positive puncta (Fig 4G and $\mathrm{H}$ ). The number of CD63-positive vesicles was strongly reduced in T6BPsilenced cells (Fig 4H). Finally, we analysed the influence of T6BP silencing on the cellular localization of HLA-DM. As for CD63, in T6BP-silenced cells, HLA-DM ${ }^{+}$vesicles were strongly re-localized around the nucleus and their number was reduced as compared to mocktreated cells (Fig S3F and G). In summary, in T6BP-silenced cells, LAMP-1 ${ }^{+}$, HLA-DM ${ }^{+}$ $\mathrm{CD} 3^{+} \mathrm{MHC}-\mathrm{II}^{+}$and Lysotracker ${ }^{+} \mathrm{MHC}-\mathrm{II}^{+}$vesicles showed a repositioning at the proximity of the nucleus (Fig 4). These results strongly suggest that, upon T6BP silencing, the MIIC is re-localized closer to the nucleus. This repositioning of the MIIC might highlight a potential defect of MIIC maturation that could sustain the dramatic changes of MHC-II peptide repertoire, observed in the absence of T6BP.

\section{T6BP silencing leads to exacerbated CD74 degradation in HeLa-CIITA cells.}

CD74 (also called Ii) is essential for the traffic and the maturation of MHC-II molecules within the cell (Bakke \& Dobberstein, 1990; Lotteau et al., 1990; Neefjes et al., 1990; Roche et al., 1991). In the MIIC, CD74 degradation is also strictly regulated to ensure appropriate loading of MHC-II molecules with high affinity peptides (Manoury et al., 2003; Nakagawa et al., 1998; Riese et al., 1996; Shi et al., 2000). Note that in humans, among the four CD74 isoforms (Iip33, Iip35, Iip41 and Iip43) Iip33 is the most abundant. (Thibodeau et al., 2019). We thus assessed the effect of T6BP silencing on CD74 expression. As previously, HeLaCIITA cells were transfected with siRNAs and CD74 expression was assessed by western 
blotting. In control cells, Iip33 was readily detected together with the cleavage product Iip16 (Fig 5A). In contrast, upon T6BP silencing, Iip33 and Iip16 detections were strongly decreased (Fig 5A). Normalized to the housekeeping gene (actin), the decrease of Iip33 expression reached up to 50\% (Fig 5A, right panel). As control, using western blotting, we also assessed the expression level of HLA-DR molecules. As expected from our cytometry and microscopy results (Fig 3 and 4), the global expression of HLA-DR molecules was similar in siCTRL- and siT6BP-treated cells (Fig 5B). In addition, we asked whether T6BP silencing might also affect the expression of HLA-DM, the chaperone involved in quality control of peptide loading on MHC-II molecules. As for HLA-DR, the expression levels of HLA-DM were not affected by the extinction of T6BP expression (Fig 5C). Using confocal microscopy, we confirmed that T6BP-silenced cells exhibit about 50\% lower expression levels of CD74 than control cells (Fig 5D and E). Note that, in control cells, the T6BP staining did not co-localize with CD74 (Fig 5D and F).

In order to test whether the expression levels of CD74 were affected or whether CD74 might be aberrantly degraded in T6BP-silenced cells, we next analysed the kinetics of degradation of MHC-II/CD74 complexes. HeLa-CIITA cells were silenced for T6BP expression and the degradation kinetics of HLA-DR/CD74 complexes evaluated using pulse-chase experiments (Fig 5G and $\mathrm{H}$ ). 48h post-transfection, the cells were pulsed with radiolabelled amino acids, chased for different time points, lysed and submitted to immunoprecipitation using the Tü36 antibody that offers the opportunity to follow the fate of the invariant chain that form a trimer with the $\alpha$ and $\beta$ chains of the HLA-II molecules (Benaroch et al, 1995). The degradation of MHC-II/CD74 complexes was analysed at $0 \mathrm{~h}, 1 \mathrm{~h}, 2 \mathrm{~h}$ and $4 \mathrm{~h}$ of chase. In control cells at $1 \mathrm{~h}$, we noticed an increase in bands corresponding to CD74 isoforms: Iip41/Iip43 and Iip33/Iip35 $\mathrm{kDa}$ (Fig 5G), which has been previously attributed to the association of pulse-labelled CD74, present in molar excess with unlabelled HLA-DR- $\alpha$ and $-\beta$ chains (Benaroch et al., 1995). At the same time point $(1 \mathrm{~h})$ in T6BP-silenced cells, we did not observe this accumulation of CD74 isoforms with the $\alpha$ and $\beta$ chains (Fig 5G). In fact, in the control conditions, the invariant chain degradation product, Iip16, was detected only after $1 \mathrm{~h}$ of chase (Fig 5G). In contrast, Iip16 was immediately detected after the pulse (time $0 \mathrm{~h}$ ) in the T6BP-silenced cells (Fig 5G) suggesting a rapid CD74 degradation. Overall, in control cells, we observed an accumulation of CD74 Iip16 degradation product at time $1 \mathrm{~h}$ followed by a decrease of its relative quantity $(\mathrm{Fig} 5 \mathrm{H}$ ), probably reflecting a progressive degradation of CD74. In contrast, T6BP silencing led to early and exacerbated CD74 degradation in HeLa-CIITA cells (Fig $5 \mathrm{H})$. Remarkably, the expression of CD74 has been shown to influence the immunopeptidome of MHC-II molecules (Muntasell et al, 2004).

\section{T6BP interactome reveals novel binding partners.}

To decipher the mechanism by which T6BP influences MHC-II-restricted endogenous antigen presentation, we decided to define the interactome of T6BP in HeLa-CIITA cells. To this end, HeLa-CIITA cells were transfected with a plasmid encoding GFP-T6BP, a construct that was previously functionally characterized (Morriswood et al., 2007), and as negative control, a plasmid encoding GFP (Fig S4A). We then performed a large-scale immunoprecipitation (IP) using GFP as bait. Three biological replicates were performed. As quality control, the lysates and the various fractions of the immunoprecipitation procedure 
were analysed using coomassie blue staining and anti-GFP staining in Western Blot (Fig S4B). The immunoprecipitation products of the three replicates were then submitted to mass spectrometry (LC-MS/MS) analysis to identify the proteins interacting with GFP-T6BP. (Fig S4C). The Uniprot Homo sapiens database was used to assign a protein name to the peptides sequenced by MS. The results were compared against the 3 IP-replicates of GFP transfected cells and a bank of 8 control experiments, also performed with GFP-Trap agarose magnetic beads, using the online contaminants database CRAPome.org (Mellacheruvu et al, 2013). Using a fold-change (FC) threshold of $\geq 10$, and a Significance Analysis of INTeractome (SAINT) probability threshold of $\geq 0,8$ (Choi et al, 2011), we identified 116 high-confidence T6BP proximal proteins (Fig 6 and Table S1). These included previously known T6BPinteractants such as the E3 ligase ITCH (Shembade et al, 2008), the kinase TBK1 (Richter et $a l, 2016)$ and TRAF2, all involved in NF-кB signalling pathways (Shembade et al, 2010). This screen also confirmed that T6BP interacts, probably in degradation bodies, with the autophagy receptor p62 (SQSTM1) (Mildenberger et al, 2017). It revealed novel potential partners that might bind directly or as part of larger T6BP-associated protein complexes. These candidates could be grouped in 6 major functional cellular pathways based on Ingenuity (Fig 6). As expected, from the known T6BP functions, some candidate-partners were enriched in the Ubiquine/Proteasome ( $\mathrm{p}$-value $=3,16 \mathrm{E}-18$ ) and NF- $\mathrm{kB}$ signalling ( $\mathrm{p}$ value $=1,15 \mathrm{E}-02)$ pathways, but also in the unfolded protein response (UPR)/protein folding ( $p$-value $=2,69 \mathrm{E}-04)$, endocytosis $(\mathrm{p}$-value $=6,03 \mathrm{E}-05)$, and antigen presentation ( $\mathrm{p}$-value $=$ 2,34E-06) pathways (Fig 6). The antigen presentation group includes HLA-A, -C, -DQ $\alpha 1$, DR $\beta 1$ molecules (Fig 6). In the UPR/protein folding group, the ER-resident chaperone protein Calnexin is 22 times enriched in T6BP-GFP IP as compared to GFP only IP (Fig 6 and Table S1). Calnexin drew our attention because: 1) it has been shown to interact with CD74 (Anderson \& Cresswell, 1994); 2) the inhibition of Calnexin interaction with CD74 has been shown to induce CD74 degradation, without influencing the formation of MHC-II complexes (Romagnoli \& Germain, 1995).

\section{Calnexin silencing induces CD74 degradation and reduces MHC-II-restricted presentation to $\mathrm{CD4}^{+} \mathrm{T}$ cells.}

To verify that Calnexin interacts with T6BP, as previously, we immunoprecipitated GFPT6BP and GFP from HeLa-CIITA transfected cells and analysed, using Western blot, the presence of Calnexin in the IP fractions. Not surprisingly, the IP of the GFP transfected cells lead to the immunoprecipitation of larger GFP-positive fraction than the IP of the T6BP-GFP transfected cells (Fig 7A, anti-GFP Ab). Nonetheless, we observed a 3-fold enrichment of Calnexin in cells transfected with GFP-T6BP as compared to GFP-transfected cells (Fig 7A). Taking into account the total amount of GFP signals in both conditions, the relative enrichment of Calnexin was 100-fold higher in the GFP-T6BP fractions than GFP only. All together, these results confirm that Calnexin interacts with T6BP directly or as part of a larger protein complex. We then investigated a potential role of Calnexin in MHC-II-restricted antigen presentation. We screened several siRNA targeting Calnexin and identified a siRNA whose transfection, depending on the experiments, lead to strong (Fig 7B) or partial (Fig 7C) decrease of Calnexin expression (siCANX), without affecting significantly the viability of transfected Hela-CIITA cells (not shown). Using Western blot, we first analysed the influence 
of Calnexin-silencing on CD74 expression. In siCANX-treated cells, we observed a strong reduction of CD74 expression levels (Fig 7C) reminiscent of what we observed in cells silenced for T6BP expression (Fig5A). To monitor the influence of Calnexin on antigen presentation, the HeLa-CIITA cells were transfected with siCANX side by side with siCTRL or siT6BP used as negative and positive controls, respectively. As in Fig 1E, the cells were then transfected with the plasmid encoding the HCMV pp65 antigen fused to GFP, the levels of pp65-GFP expression were monitored using flow cytometry (not shown) and the cells were co-cultured with the anti-pp65 $\mathrm{CD}^{+} \mathrm{T}$ cell line. Calnexin-silencing induced a marked inhibition of $\mathrm{CD}^{+} \mathrm{T}$ cell activation by pp65-transfected cells (Fig 7D, left and middle panels). In contrast, the inhibition of Calnexin expression did not influence the capacity of peptide-loaded cells to activate pp65-specific $\mathrm{CD}^{+} \mathrm{T}$ cells (Fig 7D right panel). The magnitude of siCANX-mediated $\mathrm{CD}^{+} \mathrm{T}$ cell inhibition did not reach the levels induced by siT6BP, potentially suggesting that additional mechanism might be involved in T6BP modulation of antigen presentation. We propose that T6BP silencing may affect CD74/Calnexin interactions resulting in CD74 degradation and aberrant MHC-II peptide loading and antigen presentation to $\mathrm{CD} 4^{+} \mathrm{T}$ cells. 


\section{Discussion}

We demonstrate here that T6BP regulates the loading and presentation of endogenous viral antigens by MHC-II molecules. This function of T6BP in antigen presentation has a direct implication in the activation of virus specific $\mathrm{CD}^{+} \mathrm{T}$ cells. The action of T6BP is broader than what we initially anticipated as it affects the presentation of various antigens whose processing is dependent or independent on autophagy degradation. We further show that T6BP shapes the immunopeptidome of MHC-II molecules. We provide evidence that T6BP controls MHC-II molecule peptide loading in particular through its interactions with calnexin that stabilizes the invariant chain CD74. However, this is probably not the only way by which T6BP affects MHC-II restricted antigen presentation as it also participates in the regulation of the trafficking of MHC-II-loading compartments and more globally of acidified vesicular compartments.

We recently reported that HIV-infected cells present MHC-II-restricted HIV Gag- or Envderived antigens to HIV-specific $\mathrm{CD}^{+} \mathrm{T}$ cells (Coulon et al., 2016). The processing of these native antigens does not rely on the autophagy pathway. However, when targeted to autophagosomes, using LC3, HIV Gag processing is dependent on autophagosomal degradation. In fact, using DC and HeLa-CIITA cells we showed that as compared to native HIV Gag protein, the targeting of HIV Gag to autophagosome leads to a more robust activation of Gag-specific T cells (Coulon et al., 2016). We concluded that depending on the cellular localisation, the same antigens may be degraded by various endogenous routes leading to MHC-II loading. We reveal here that T6BP modulates Gag antigen presentation independently of its cytosolic or autophagosomal cellular localisation. Likewise, T6BP affects the presentation of an HCMV pp65-derived peptide. Our analysis of the immunopeptidome of HeLa-CIITA cells uncovers that T6BP has a broad influence on the repertoire and relative abundance of the peptides presented by MHC-II molecules. Without excluding the possibility, these observations do not indicate whether T6BP also affects the exogenous pathway of antigen presentation by MHC-II molecules. Indeed, seminal studies demonstrated that the landscape of peptide naturally presented by MHC-II molecules also contains a fraction of peptides that are derived from intracellular proteins (Muntasell et al, 2002; Rammensee et al., 1999; Rudensky et al., 1991). In our model system, HeLa-CIITA cells, we could not ask whether the silencing of T6BP affects the exogenous pathway because these cells lack the ability to present exogenous viral antigen to $\mathrm{CD}^{+} \mathrm{T}$ cells (Coulon et al., 2016). This is a weakness but also a strength of this model system since it allowed focusing our work on the endogenous pathway. Nevertheless, we intended to ask whether T6BP might affect antigen presentation by primary APC. We used several means to silence T6BP in monocyte-derived dendritic cells (MDDC) including siRNA and shRNA. Unfortunately, whatever the protocol and independently of T6BP expression, the tools used to transfect or transduce MDDC induced a maturation of the cells and a modification of MHC-II trafficking which prohibited from drawing any conclusion on the potential role of T6BP in MDDC. Nonetheless, our results strongly suggest that at least in epithelial cells that can turn into APC upon inflammation (Wijdeven et al., 2018), T6BP expression shapes the peptide repertoire, but also the relative abundance and the relative affinity of epitopes presented by MHC-II molecules. 
Indeed, our immunopeptidomic data suggest that the expression of T6BP favours the loading of peptide with a higher binding capacity to HLA-II molecules. As expected based on previous work with cell lines (Alvaro-Benito et al., 2018) or analysing tissue samples (Marcu et al, 2020), we observed a natural variation of the MHC-II immunopeptidome between two mock-treated samples with about $60 \%$ of shared peptides. However, in these mock samples, we did not notice a significant difference in terms of relative quantity of the peptides at the level of the core epitope. This is in sharp contrast to the comparison of wild-type and T6BPsilenced cells where half of the MHC-II binding core epitopes were differentially presented. Remarkably, we also observed a natural variation of the immunopeptidome of MHC-I molecules, with about $50 \%$ of shared peptides. Notably, T6BP silencing did not have a strong influence on the repertoire of peptides presented by MHC-I molecules, as the percentage of shared peptides with the control siRNA-treated cells was also around 50\%. In addition, the affinity of MHC-I ligands was comparable in wild type cells and cells silenced for T6BP expression. Our results strongly suggest that the action of T6BP is restricted to the MHC-II antigen presentation pathway and affects both the abundance and the affinity of core epitopes to HLA molecules.

The chaperones HLA-DM and the invariant chain, CD74, tightly regulate the loading of peptides on MHC-II molecules. Previous studies have shown that the levels of expression of both HLA-DM and CD74 affect the repertoire and the affinity of the peptide presented by various HLA-DR and HLA-DQ alleles (Alvaro-Benito et al., 2018; Muntasell et al., 2004; Ramachandra et al, 1996). Remarkably, in the absence of T6BP, we noticed a reduced expression level of CD74 whereas HLA-DM and HLA-DR expression levels remained unchanged. Our analysis of the expression kinetics of MHC-II complexes, using pulse/chase experiments, further showed that, the lack of T6BP induces a rapid and exacerbated degradation of CD74. These observations probably explain the modifications of the immunopeptidome observed in the absence of T6BP expression. However, the diversity of the immunopeptidome could also be due to variations in the origin of the peptides presented by MHC-II molecules (Muntasell et al., 2004); in particular since we observed a global modification of the cellular distribution of acidified vesicular compartments in the absence of T6BP. However, in our data sets, we analysed the cellular distribution of the proteins from which the identified MHC-II peptides originate and we did not notice any significant difference in control and T6BP silenced cells (not shown). Overall, our observations suggest that T6BP expression influences the degradation kinetics of CD74 with a direct influence on the diversity and affinity of the immunopeptidome of MHC-II molecules.

The ER chaperone calnexin that participates in the quality control of protein folding in the ER has been shown to play an important role in the assembly of the nonameric $\alpha \beta-C D 74$ complexes (Arunachalam \& Cresswell, 1995). Calnexin retains and stabilizes CD74 in the ER until it assembles with the $\alpha$ - and $\beta$-chains (Romagnoli \& Germain, 1995). It also binds newly synthetized $\alpha$ - and $\beta$-chains of HLA molecules until it forms, with CD74, a complete nonamer (Anderson \& Cresswell, 1994). Interestingly, it has been shown that the treatment with Tunicamycin or the expression of CD74 mutants, lacking N-linked glycosylation, that both impede the interactions with calnexin, induces CD74 degradation (Romagnoli \& Germain, 1995). Using siRNA silencing, we confirmed here that in the absence of calnexin, CD74 is degraded. In addition, we demonstrate that the silencing of calnexin in APC has a strong 
influence on their capacity to activate antigen-specific $\mathrm{CD}^{+} \mathrm{T}$ cells. Remarkably, using mass spectrometry, we identified calnexin as a binding partner of T6BP, among 116 highconfidence T6BP proximal proteins. It has been proposed that the ER distribution of calnexin might determine its functions as chaperone involved in protein quality control or in the regulation of $\mathrm{Ca} 2+$ transfer to mitochondria (Lynes et al, 2013). We demonstrate here that T6BP contributes in defining the stability of CD74 and thus on the quality of peptide loading on MHC-II. A remaining question is how T6BP affects CD74/calnexin interactions. Several post-translational modifications influence both the cellular distribution and the functions of calnexin: phosphorylation leads to a re-distribution from peripheral ER tubules to a juxtanuclear ER (Myhill et al, 2008) while palmitoylation seems to assign specific tasks to calnexin within the ER in particular a role in protein folding (Lynes et al., 2013) and a localization in the proximity of the ribosome complexes (Lakkaraju et al, 2012). To our knowledge, there is no published evidence that calnexin is ubiquitinated on its cytosolic tail. We believe that this possibility should be investigated to provide a molecular link between T6BP and calnexin functions in the formation of MHC-II loading complexes and thus antigen presentation. Note that, calnexin has also been shown to contribute to the assembly of MHC-I molecules by protecting free MHC-I molecules from degradation (Vassilakos et al, 1996) and by binding to the TAP-tapasin complex (Diedrich et al, 2001). However, calnexin action on MHC-I molecule assembly and transport to the cell surface seems dispensable (Prasad et al, 1998; Scott \& Dawson, 1995) which would explain the lack of influence on the MHC-I immunopeptidome of calnexin, in the absence of T6BP.

We suggest here that calnexin is a key factor involved in T6BP-mediated regulation of MHCII loading that strongly influences the repertoire and affinity of presented peptides. However, we do not exclude that other cellular factors or pathways also participate in T6BP action on MHC-II molecules. Interestingly, T6BP has been shown to influence the maturation of endosomes (Jongsma et al., 2016); and using IF, we show that T6BP affects the trafficking of MHC-II-rich compartments and more globally of acidified vesicular compartments corresponding to late endosome, lysosomes and autophagosomes. Accumulating evidence suggest that the positioning of intracellular vesicles controls their functions (Neefjes et al, 2017) and in particular the intravesicular $\mathrm{pH}$ (Johnson et al, 2016). The repositioning of the MIIC mediated by T6BP could influence the activation of intravesicular $\mathrm{pH}$-dependent proteases that participate in the cleavage of CD74. To this regard, it is interesting to note that we identified in the interactome of T6BP, ATP6V0A1 a subunit of the vATPase that plays a critical role in mediating vesicular acidification (Forgac, 2007). On the other hand, CD74 has also been shown to play itself a role in endosomal membrane trafficking (Schröder, 2016). Thereafter, the modifications in late endosomes/lysosomes positioning in T6BP-silenced cells could be an indirect consequence of CD74 degradation. Our interactome also revealed as candidate partners for T6BP, the HLA-A, -C, -DQ $\alpha 1$ and -DR $\beta 1$ molecules. Interestingly, the cellular distribution of both HLA class-I and -II molecules is regulated by the addition of ubiquitine (Ub) moieties (De Angelis Rigotti et al, 2017; Shin et al, 2006; Walseng et al, 2010). In the case of HLA-DR, ubiquitination of the lysine residue (K235) of HLA-DR $\beta 1$ plays a major role in regulating the cellular localisation of mature HLA-DR molecules (Lapaque et al, 2009). Although T6BP has the capacity to bind ubiquitinated proteins, we favour the hypothesis that T6BP and HLA molecules might be part of larger molecular 
complexes or lipid compartments in particular since we observed neither a co-localization of T6BP with HLA-DR molecules nor a significant difference in the kinetics of HLA-DR endocytosis in HeLa-CIITA cells silenced for T6BP expression.

The autophagy receptor T6BP as well as OPTN, NDP52, p62 and NBR1 harbour Ub- and LC3-binding motifs, whose functions are well characterized in selective autophagy (Kirkin \& Rogov, 2019). In addition, T6BP and NDP52 share a N-terminal SKIP carboxyl homology (SKICH) domain target of TANK-binding kinase-1 (TBK1) phosphorylation that acts as an upstream regulator of mitophagy (Fu et al, 2018). Beyond selective autophagy, ARs also modulate the traffic and maturation of autophagosomes and endosomes. The Ub-binding domains of T6BP, OPTN and p62 have been implicated in regulating the NF-кB pathway where together with A20 they down-modulate the activation of this pathway during inflammation (Weil et al, 2018). T6BP, NDP52, and p62 were shown to orchestrate the maturation of early endosomes into late endosomes, in a process involving their Ub-binding domains (Jongsma et al., 2016). T6BP, NDP52 and OPTN also bind to Myosin-VI, which recruits Tom-1-expressing endosomes and lysosomes, facilitating autophagosome maturation in lytic vesicles (Morriswood et al., 2007; Sahlender et al., 2005; Tumbarello et al., 2012). A recent work suggested that Ub and Myosin-VI compete for the binding to T6BP (Hu et al, 2018). In our interactome, we identified known protein partners of T6BP involved for instance in NF-kB signalling pathways (e.g. TBK1, TRAF2, ITCH, SQSTM1/p62). Other described T6BP partners were not identified such as Myosin-VI, likely reflecting that T6BP interactions occur in a cell type-specific manner (O'Loughlin et al, 2018). Nonetheless, we revealed novel potential partners of T6BP involved in the Ubiquine/Proteasome (e.g. E3 Ubligases UBR1, 2 and 4), the UPR/protein folding (e.g. BAG6, EIF2a, calnexin), endocytosis (e.g. COPB1) and antigen presentation pathways (e.g. HLA molecules). We also found that T6BP interacts with NBR1 that has been found together with p62 in larger protein complexes and ubiquitinated protein aggregates (Weil et al., 2018). Much remains to be learned on the molecular mechanisms and motif involved in the variety of T6BP molecular interactions and functions, in particular in MHC-II antigen presentation that we unravel here. Side by side comparison of AR functional domains will most likely bring new insights.

Our work reveals that T6BP regulates the cellular positioning of endosomal/lysomal vesicles and the stability of CD74, probably through an interaction with calnexin, and exert a direct influence on MHC-II-restricted antigen presentation. This novel role of T6BP in the activation of adaptive antiviral immunity further highlights the diverse non-redundant functions exerted by autophagy receptors. 


\section{Materials and Methods}

\section{Cells}

HeLa-CIITA cells were provided by P.Benaroch (Institut Curie, Paris, France), are homozygotes for HLA-DR $\beta 1 * 0102$ allele, and were cultured with RPMI GlutaMax 1640 (Gibco) complemented with 10\% FBS (Dutscher), 1\% Penicillin/Streptomycin, $50 \mu \mathrm{g} / \mathrm{mL}$ Hygromycin B (Thermo Fisher).

\section{HIV-1- \& HCMV-specific CD4 ${ }^{+}$T cell clones}

Gag-specific CD4 ${ }^{+} \mathrm{T}$ cell clones (F12) are specific for HIV Gag-p24 (gag2: aa 271-290) and restricted by HLA-DR $\beta 1^{*} 01$ as previously described (Coulon et al., 2016; Moris et al., 2006). HCMV-specific CD4 ${ }^{+} \mathrm{T}$ cell clones are specific for HCMV pp65 antigen (pp65: aa 108-127) and restricted by HLA-DR $\beta 1 * 01$. Pp65-specific clones were isolated from PBMCs of healthy donors after several round of in-vitro stimulation with synthetic peptide corresponding to immunodominant epitopes from the pp65 protein. Pp65-specific cells were isolated using the IFN- $\gamma$ secreting assay from Miltenyi Biotec and cloned by limiting dilution. F12 and pp65 clones were restimulated and expanded, as previously described (Moris et al., 2006), using irradiated feeders and autologous or HLA-matched lymphoblastoid cell lines loaded with cognate peptides in T cell cloning medium: RPMI 1640 containing 5\% human AB serum (Institut Jacques Boy), recombinant human IL-2 (100 IU/ml, Miltenyi Biotec), PHA $(0,25$ $\mu \mathrm{g} / \mathrm{ml}$, Remel), non-essential amino acids, and sodium pyruvate (both from Life Technologies). At least $1 \mathrm{~h}$ before coculture with HeLa-CIITA cells, T cell clones were thawed and allowed to rest at $37^{\circ} \mathrm{C}$ in RPMI containing DNAse $(5 \mu \mathrm{g} / \mathrm{mL}$, New England Biolabs).

\section{Viral antigens and plasmids}

The pTRIP-CMV-Gag (a kind a gift from Nicolas Manel (Institut Curie, Paris, France), pGagLC3 and Gag-LC3 $3_{\mathrm{G} 120 \mathrm{~A}}$ plasmids were already described (Coulon et al., 2016). The pp65 encoding cDNA (a kind gift from Xavier Saulquin, Université de Nantes, Nantes) was cloned in the lentiviral vector cppT-EF1 $\alpha$-IRES-GFP. The GFP-T6BP encoding plasmid is a kind gift from Folma Buss (University of Cambridge, UK) (Tumbarello et al., 2015).

\section{Cell transfections}

HeLa-CIITA cells were incubated in 6-well plates using $2-4.10^{5}$ cells/well using OPTIMEM (Gibco) complemented with 10\% FBS, 1\% Penicillin/Streptomycin. Twenty-four hours later, cells were transfected with 40 pmol of siRNA targeting NDP52 (L-010637-00-0005), OPTN (L-016269-00-0005), p62 (L-010230-00-0005), T6BP (L-016892-00-0020 Dharmacon or SI02781296, Qiagen), CANX (SI02663367 and SI02757300, Qiagen) or a scrambled siRNA as control (D-001810-10-20, Dharmacon), using Lipofectamine RNAiMax (13778-150, Thermo Fisher) as transfection reagent. After $24 \mathrm{~h}$ of transfection, cells were transfected with the cDNA encoding the viral antigens $(1 \mu \mathrm{g}$ per well of a 6 -well plate) using Viromer RED (Lipocalyx) and following manufacturer instructions. Twenty-four hours later, Gag and pp65 expressions were assessed using anti-Gag antibody (KC57-RD1, Beckman-Coulter) and antipp65 antibody (mouse, Argene) combined with goat anti-mouse antibody (AF488, Thermo Fisher), respectively. 


\section{Flow cytometry}

Cell viability was evaluated using LIVE/DEAD (Thermo Fisher) or Zombie (Biolegend) and the following antibodies were used: CD4-APC, TNF- $\alpha$-PE, IFN- $\gamma$-PE, IL-2-PE (BD Biosciences), MIP-1 $\beta$-FITC (R\&D Systems), HLA-DR specific L243 and Tü36 (both in house and kindly provided by Philippe Benaroch, Institut Curie, Paris) and goat anti-mouse (AF488, Thermo Fisher). Forty-eight hours after siRNA transfection, cell-surface staining assays were performed using standard procedures $\left(30 \mathrm{~min}, 4^{\circ} \mathrm{C}\right)$. Cytokine production was detected using intracellular staining. Briefly, cells were fixed with 4\% PFA (10min, RT), washed, and permeabilized with PBS containing 0,5\% BSA and 0,05\% Saponin, prior to antibody staining. Samples were processed on Fortessa cytometer using FACSDiva software (BD Biosciences) and further analysed using FlowJo2 software (Tree Star).

\section{Antigen presentation assays}

\section{IFN- $\gamma$ ELISPOT assay}

ELISPOT plates (MSIPN4550, Millipore) were pre-wet and washed with PBS, and coated overnight at $4{ }^{\circ} \mathrm{C}$ with anti-IFN- $\gamma$ antibody (1-DIK, Mabtech). Plates were washed using PBS and then saturated with RPMI complemented with $10 \%$ FBS. Plates were washed and HeLaCIITA cells $\left(10^{5}\right.$ cells/well $)$ were co-cultured with $\mathrm{T}$ cell clones $\left(5.10^{3}\right.$ and $1.10^{3}$ cells/well $)$ overnight at $37^{\circ} \mathrm{C}$. Cells were removed and plates were then washed with PBS- $0,05 \%$ Tween20 prior incubation with biotinylated anti-IFN- $\gamma$ antibody (7-B6-1, Mabtech) (2h, RT). Spots were revealed using alkaline-phosphatase coupled to streptavidin $(0,5 \mathrm{U} / \mathrm{ml}$, Roche Diagnostics) (1h, RT) and BCIP/NBT substrate (B1911, Sigma-Aldrich) (30min, RT). Reactions were stopped using water. Number of spots were counted using AID reader (Autoimmun Diagnostika $\mathrm{GmbH}$ ). For each experimental condition, ELISPOTs were performed mostly in triplicates or at least in duplicates.

\section{Western Blotting}

Forty-eight hours after siRNA transfection, $10^{6} \mathrm{HeLa}$-CIITA cells were washed in cold PBS and lysed in $150-300 \mu \mathrm{l}$ of lysis buffer $\left(30 \mathrm{~min}, 4^{\circ} \mathrm{C}\right)$, mixing every $10 \mathrm{~min}$. Depending on the experiments, two different lysis buffers were used: 1- PBS containing 1\% Nonidet P-40; 2- 50 $\mathrm{mM}$ Tris- $\mathrm{HCl} \mathrm{pH} 7.5$ containing $100 \mathrm{mM} \mathrm{NaCl}, 1 \%$ Triton X-100, $0.5 \mathrm{mM}$ EGTA, $5 \mathrm{mM}$ $\mathrm{MgCl}, 2 \mathrm{mM}$ ATP, both supplemented with 1x Protease Inhibitor (Roche) mixing every $10 \mathrm{~min}$. Cell lysates were then centrifuged at $20,000 \mathrm{~g}\left(20 \mathrm{~min}, 4^{\circ} \mathrm{C}\right)$, supernatants harvested and mixed with Sample Buffer (NuPAGE, Invitrogen) and Sample Reducing Agent (NuPAGE, Invitrogen) and denatured $\left(3 \mathrm{~min}, 95^{\circ} \mathrm{C}\right)$. Denatured samples were analysed by SDS gel electrophoresis using 4-12\% Bis-Tris gels (NuPAGE, Invitrogen), transferred to a nitrocellulose membrane (NuPAGE, Invitrogen) and immunoblotted. Anti-T6BP (HPA024432, Sigma-Aldrich), anti-NDP52 (HPA023195, Sigma-Aldrich), anti-CANX (PA534754, ThermoFisher), anti-OPTN (ab23666, Abcam), anti-p62 (sc-28359, Santa Cruz Biotechnology), anti-HLA-DR (TAL1B5, Invitrogen), anti-LC3 (M152, MBL International), anti-actin (3700S, Cell Signaling Technology), anti-tubulin (2148S, Cell Signaling Technology), anti-CD74 (ab22603, Abcam), anti-GFP (11814460001, Roche), goat antimouse coupled to HRP (Sigma Aldrich), and goat anti-rabbit coupled to HRP (Abcam) were used according to manufacturer instructions. Blots were revealed using Pierce ECL Plus Substrate (Invitrogen) and chemiluminescence analysed using ImageQuant LAS 4000.

\section{Confocal microscopy}

Forty-eight hours after siRNA transfections, HeLa-CIITA cells were plated on glass coverslips and then fixed with 4\% PFA (10min, RT). Cells were washed 3 times with PBS, 
saturated with goat or donkey serum and permeabilized with PBS containing 0,5\% BSA and $0,05 \%$ Saponin $(1 \mathrm{~h}, \mathrm{RT})$. Cells were washed with PBS and incubated $\left(\mathrm{OVN}, 4^{\circ} \mathrm{C}\right)$ with primary antibodies: L243 or Tü36 (both in house and kindly provided by Philippe Benaroch, Institut Curie, Paris), rabbit anti-HLA-DR (a kind gift from Jack Neefjes), LAMP-1 (H4A3, DSHB), CD63 (MA-18149), anti-CD74 (14-0747-82) all from Thermo Fisher and T6BP (HPA024432, Sigma-Aldrich). Cells were incubated with species specific antibodies: goat anti-mouse coupled to Alexa Fluor 488 or Alexa Fluor 405 (Thermo Fischer), donkey antirabbit coupled to Alexa 546 (A10040, Invitrogen) in PBS containing 0,5\% BSA and 0,05\% Saponin (1h, RT). When required sequential stainings were performed. Nuclei were stained with DAPI (17507, AAT Bioquest). After washing with PBS, samples were mounted on glass slides with Dako fluorescence mounting medium. Samples were imaged using a laser scanning confocal microscope with $63 \mathrm{X}$, NA 1.3 oil immersion objective. The number of vesicles, the intensity and the distances of each vesicle to nucleus and plasma membranes were quantified using an in-house ImageJ Python script (developed by Aziz Fouché, ENS Paris-Saclay, Paris). Potential co-localizations were determined using the object based colocalization method JACoP (Just Another Co-localization Plugin) and coloc2 (Pearson's coefficient) of the ImageJ software, for punctuated/vesicular and cytosolic/diffuse staining, respectively.

\section{Pulse-Chase experiment}

48h post siRNA transfection HeLa-CIITA cells were preincubated in Met/Cys-free RPMI 1640 medium containing 1\% Penicillin/Streptomycin, 1\% glutamine and 10\% dialyzed FCS for $1 \mathrm{~h}$. Cells (one million) were then pulsed for $30 \mathrm{~min}$ with $0.5 \mathrm{mCi}$ of ${ }^{35} \mathrm{~S}-\mathrm{Met} / \mathrm{Cys}$ (ICN) and chased in unlabeled medium supplemented with $5 \mathrm{mM}$ cold methionine. Cells were collected at the indicated time points and then lysed in a buffer containing $20 \mathrm{mM}$ Tris- $\mathrm{HCl}$ (pH 7.5), $150 \mathrm{mM} \mathrm{NaCl}, 2 \mathrm{mM} \mathrm{MgCl} 2,1 \%$ Triton X-100, and an inhibitor cocktail (Roche). Each sample was normalized for the protein concentration. Lysates were precleared with mouse serum, and MHC class II/Ii complexes were immunoprecipitated with the TÜ36 antibody. Samples were boiled in sample buffer and separated by 12\% SDS-PAGE (Novex). Quantification of the results was made using a phosphoimager (Fuji).

\section{Electron Microscopy}

HeLa-CIITA cells $\left(2.10^{5}\right.$ cells/well) were cultured on glass cover slips in 6-well plates on RPMI GlutaMax 1640 (Gibco) complemented with 10\% FBS (Dutscher), 1\% Penicillin/Streptomycin and $50 \mu \mathrm{g} / \mathrm{mL}$ Hygromycin B (Thermo Fisher). Twenty-four hours later, cells were transfected with 40 pmol of siRNA Control or targeting T6BP using Lipofectamine RNAiMax (13778-150, Thermo Fisher), cells were cultured for 48 hours and fixed with $2.5 \%$ Glutaraldehyde, $1 \%$ PFA for $1 \mathrm{~h}$ at room temperature. The cover slips were washed 3 times with $0.2 \mathrm{M}$ phosphate buffer $\mathrm{pH} 7.4$, followed by a 1-hour incubation in $1 \%$ Osmium, 1.5\% Ferrocyanide of Potassium. After 3 washes in water, the cover slips were successively treated with $50 \%, 70 \%, 90 \%, 100 \%$ and $100 \%$ Ethanol for 10 minutes each. The cover slips were then incubated for 2 hours on $50 \%$ epoxy in ethanol, followed by 2 hours in pure epoxy, and finally in pure epoxy overnight for polymerization at $60^{\circ} \mathrm{C}$. Ultrathin $(70 \mathrm{~nm})$ sections were cut using a diamond knife $\left(45^{\circ}\right.$ angle) on a Leica UC6 ultramicrotome. Sections were collected on Formvar ${ }^{\mathrm{TM}}$ carbon-coated copper grids. Some sections were stained with uranyl acetate at 2\% (Merk) for $15 \mathrm{~min}$ and lead Citrate (Agar) and washed three times with milliQ water and dried at room temperature. Observations were performed with a JEOL JEM1400 transmission electron microscope operating at $120 \mathrm{kV}$. Images were acquired using a post-column high-resolution (9 $10^{6}$ pixels) camera (Rio9; Gatan) and processed with Digital Micrograph (Gatan) and ImageJ. 


\section{Immunopeptidome}

\section{Isolation of HLA ligands}

HLA class-I and -II molecules of HeLa-CIITA cells were isolated using standard immunoaffinity purification (Falk et al, 1991; Nelde et al, 2019). Snap-frozen samples were lysed in $10 \mathrm{mM}$ CHAPS/PBS (AppliChem, Gibco) with 1x protease inhibitor (Roche). HLA class-I and -II-associated peptides were isolated using the pan-HLA class I-specific mAb W6/32, the pan-HLA class II-specific mAb Tü39, and the HLA-DR-specific mAb L243 (mouse monoclonal, in-house) covalently linked to CNBr-activated Sepharose (GE Healthcare). HLA-peptide complexes were eluted by repeated addition of $0.2 \%$ TFA (trifluoroacetic acid, Merck). Eluted HLA ligands were purified by ultrafiltration using centrifugal filter units (Millipore). Peptides were desalted using ZipTip C18 pipette tips (Millipore), eluted in $35 \mu \mathrm{l} 80 \%$ acetonitrile (Merck)/0.2\% TFA, vacuum-centrifuged and resuspended in $25 \mu \mathrm{l}$ of $1 \%$ acetonitrile $/ 0.05 \%$ TFA and samples stored at $-20{ }^{\circ} \mathrm{C}$ until LCMS/MS analysis.

\section{Analysis of HLA ligands by LC-MS/MS}

Isolated peptides were separated by reversed-phase liquid chromatography (nano-UHPLC, UltiMate 3000 RSLCnano; ThermFisher) and analysed in an online-coupled Orbitrap Fusion Lumos mass spectrometer (Thermo Fisher). Samples were analysed in five technical replicates and sample shares of $20 \%$ trapped on a $75 \mu \mathrm{m} \times 2 \mathrm{~cm}$ trapping column (Acclaim PepMap RSLC; Thermo Fisher) at $4 \mu \mathrm{l} / \mathrm{min}$ for $5.75 \mathrm{~min}$. Peptide separation was performed at $50{ }^{\circ} \mathrm{C}$ and a flow rate of $175 \mathrm{nl} / \mathrm{min}$ on a $50 \mu \mathrm{m} \times 25 \mathrm{~cm}$ separation column (Acclaim PepMap RSLC; Thermo Fisher) applying a gradient ranging from 2.4 to $32.0 \%$ of acetonitrile over the course of $90 \mathrm{~min}$. Samples were analysed on the Orbitrap Fusion Lumos implementing a topspeed CID method with survey scans at $120 \mathrm{k}$ resolution and fragment detection in the Orbitrap (OTMS2) at 60k resolution. The mass range was limited to $400-650 \mathrm{~m} / \mathrm{z}$ with precursors of charge states $2+$ and $3+$ eligible for fragmentation.

\section{Database search and spectral annotation}

LC-MS/MS results were processed using Proteome Discoverer (v.1.3; Thermo Fisher) to perform database search using the Sequest search engine (Thermo Fisher) and the human proteome as reference database annotated by the UniProtKB/Swiss-Prot. The searchcombined data of five technical replicates was not restricted by enzymatic specificity, and oxidation of methionine residues was allowed as dynamic modification. Precursor mass tolerance was set to $5 \mathrm{ppm}$, and fragment mass tolerance to $0.02 \mathrm{Da}$. False discovery rate (FDR) was estimated using the Percolator node (Käll et al, 2007) and was limited to 5\%. For HLA class-I ligands, peptide lengths were limited to 8-12 amino acids. For HLA class-II, peptides were limited to 12-25 amino acids of length. HLA class-I annotation was performed using NetMHCpan 4.0 (Jurtz et al., 2017) annotating peptides with percentile rank below 2\% as previously described (Ghosh et al, 2019).

For HLA class-II peptides, the Peptide Lansdscape Antigenic Epitope Alignment Utility (PLAtEAU) algorithm (Alvaro-Benito et al., 2018) was used to identify and to estimate the relative abundance of the core epitopes based on the LC-MS/MS intensities. The results are presented as Volcano plots using Perseus software (Tyanova et al, 2016). The relative affinities of the core epitope to HLA-DR $\beta 1 * 0102$, expressed by HeLa-CIITA cells, was estimated using NetMHCIIpan 4.0 (Reynisson et al., 2020). 


\section{Interactome}

\section{Co-immunoprecipitation}

HeLa-CIITA cells were harvested $24 \mathrm{~h}$ after cDNA transfection with either plasmid encoding GFP-T6BP (kind gift from F.Buss, Cambridge, UK) or encoding GFP. $2.10^{7}$ cells were washed in cold PBS and lysed in $300 \mu \mathrm{l}$ of lysis buffer $(50 \mathrm{mM}$ Tris- $\mathrm{HCl} \mathrm{pH} 7.5,100 \mathrm{mM}$ $\mathrm{NaCl}, 1 \%$ Triton X-100, $0.5 \mathrm{mM}$ EGTA, $5 \mathrm{mM} \mathrm{MgCl}, 2 \mathrm{mM}$ ATP, and 1x Protease Inhibitor (Roche) (30min, ice), mixing every $10 \mathrm{~min}$ and centrifuged at $20,000 \mathrm{~g}\left(20 \mathrm{~min}, 4^{\circ} \mathrm{C}\right)$. Lysates were recovered, $300 \mu \mathrm{l}$ of wash buffer $(50 \mathrm{mM}$ Tris- $\mathrm{HCl} \mathrm{pH} 7.5,150 \mathrm{mM} \mathrm{NaCl}, 0.5 \mathrm{mM}$ EDTA) was added and the pellets were discarded. GFP-Trap agarose magnetic beads (Chromotek) were vortexed, $25 \mu \mathrm{l}$ of bead slurry was washed 3 times with cold wash buffer. Each diluted lysate was added to $25 \mu \mathrm{l}$ of equilibrated beads and tumbled end-over-end (1h, $4^{\circ} \mathrm{C}$ ). Beads were collected using a magnetic support and washed 3 times. For Western Blot analysis, SDS-sample buffer was added to aliquots and the samples were boiled (5 min, $\left.99^{\circ} \mathrm{C}\right)$.

\section{On-bead digestion for mass spectrometry}

Following immunoprecipitation with GFP-Trap (Chromotek), digestions were performed using manufacturer instructions on the P3S proteomic core facility of Sorbonne Université. For each sample, beads were resuspended in $25 \mu \mathrm{l}$ of elution buffer I ( $50 \mathrm{mM}$ Tris-HCL pH 7.5, $2 \mathrm{M}$ urea, $5 \mu \mathrm{g} / \mathrm{ml}$ sequencing grade Trypsine, $1 \mathrm{mM}$ DTT) and incubated in a thermomixer at $400 \mathrm{rpm}\left(30 \mathrm{~min}, 30^{\circ} \mathrm{C}\right)$. Beads were collected using a magnetic support and the supernatants were recovered. For elution, beads were then washed with $50 \mu \mathrm{l}$ of elution buffer II (50 mM Tris-HCL pH 7.5, $2 \mathrm{M}$ urea, $5 \mathrm{mM}$ iodoacetamide) and collected with a magnetic support. Supernatants were harvested and mixed with the previous ones. This elution was repeated once. Combined supernatants were incubated in a thermomixer at 400 $\mathrm{rpm}$ (overnight, $32^{\circ} \mathrm{C}$ ). Reactions were stopped by adding $1 \mu \mathrm{l}$ trifluoroacetic acid and digests were desalted using home-made StageTips. StageTips were first rehydrated with $100 \mu$ of methanol and then equilibrated with $100 \mu \mathrm{l}$ of $50 \%$ acetonitrile $0.5 \%$ acetic acid. After peptide loading, StageTips were washed with $200 \mu 1$ of $0.5 \%$ acetic acid and peptides were eluted with $60 \mu \mathrm{l}$ of $80 \%$ acetonitrile $0.5 \%$ acetid acid. Eluted peptides were totally dried using a SpeedVac vacuum concentrator (Thermo), solubilised in $20 \mu \mathrm{l}$ of $2 \%$ acetonitrile $0.1 \%$ formic acid before LC-MS/MS analysis.

\section{$L C-M S / M S$}

Peptide mixtures were analysed with a nanoElute UHPLC (Bruker) coupled to a timsTOF Pro mass spectrometer (Bruker). Peptides were separated on an Aurora RP-C18 analytical column $\left(25 \mathrm{~cm}, 75 \mu \mathrm{m}\right.$ i.d., $120 \AA, 1,6 \mu \mathrm{m}$ IonOpticks) at a flow rate of $300 \mathrm{~nL} / \mathrm{min}$, at $40^{\circ} \mathrm{C}$, with mobile phase A (ACN 2\%/FA 0.1\%) and B (ACN 99.9\% / FA 0.1\%). A 30 min elution gradient was run from $0 \%$ to $3 \% \mathrm{~B}$ in $1 \mathrm{~min}, 3 \%$ to $15 \% \mathrm{~B}$ in $17 \mathrm{~min}$ then $15 \%$ to $23 \% \mathrm{~B}$ in 7 min and $23 \%$ to $32 \% \mathrm{~B}$ in 5 min. MS acquisition was run in DDA mode with PASEF. Accumulation time was set to $100 \mathrm{msec}$ in the TIMS tunnel. Capillary voltage was set to 1,6 $\mathrm{kV}$, mass range from 100 to $1700 \mathrm{~m} / \mathrm{z}$ in $\mathrm{MS}$ and MS/MS. Dynamic exclusion was activated for ions within $0.015 \mathrm{~m} / \mathrm{z}$ and $0.015 \mathrm{~V} . \mathrm{s} / \mathrm{cm}^{2}$ and released after $0,4 \mathrm{~min}$. Exclusion was reconsidered if precursor ion intensity was 4 times superior. Low abundance precursors below the target value of 20,000 a.u and intensity of 2,500 a.u. were selected several times for PASEF-MS/MS until the target value was reached. Parent ion selection was achieved by using a two-dimensional $\mathrm{m} / \mathrm{z}$ and $1 / \mathrm{k} 0$ selection area filter allowing the exclusion of singly charged ions. Total cycle time was 1,29 sec with 10 PASEF cycles. 


\section{Data Analysis}

Raw data were processed with MaxQuant version 1.6.5.0, with no normalisation, no matching between runs and with a minimum of 2 peptide ratios for protein quantification. The output protein file was filtered with ProStar 1.14 to keep only proteins detected in 2 samples or more in at least 1 of the 2 conditions. Missing values were imputed using SLSA (Structured Least Square Adaptative) algorithm for partially missing values in each condition and DetQuantile algorithm for missing values in an entire condition. In order to select relevant binding partners, data were statistically processed using limma test and filtered to retain only differentially expressed preys (FDR $1 \%$ ) with a fold change $\geq 10$ between T6BP-GFP and GFP conditions. Selected preys were uploaded to the CRAPome v2 (Contaminant Repository for Affinity Purification) online analysis tool to identify potential contaminants. For each binding partners a Significance Analysis of INTeractome (SAINT) probability threshold was assessed by the Resource for Evaluation of Protein Interaction Networks (REPRINT) using the default settings. Selected preys were then uploaded in Ingenuity Pathway Analysis software version $49932394 \quad$ (QIAGEN Inc., https://www.qiagenbioinformatics.com/products/ingenuity-pathway-analysis) to perform annotation and over-representation analysis. Finally, network visualization was designed using Cytoscape software (v. 3.7.1).

\section{Statistical analysis}

Statistical significances (p-values) were calculated using Prism Software (GraphPad).

\section{Data Availability}

The mass spectrometry proteomics data have been deposited to the ProteomeXchange Consortium via the PRIDE (Perez-Riverol et al, 2019) partner repository with the dataset identifier - PXD024330 and 10.6019/PXD024330 - and PXD024417 for the T6BPinteractome and Hela-CIITA immunopeptidome, respectively.

Reviewer account details:

Username: reviewer_pxd024330@ebi.ac.uk

Password: aCQuFy8B 


\section{Acknowledgements}

This work was granted by the ANR project AutoVirim (ANR-14-CE14-0022). We thank the "P3S" core facility of Sorbonne University for their expertise. The present work has benefited from the Imagerie facility of Imagerie-Gif, (http://www.i2bc.paris-saclay.fr), member of IBISA (http://www.ibisa.net), supported by l'Agence Nationale de la Recherche (ANR-11EQPX-0029/Morphoscope), "France-BioImaging" (ANR-10-INSB-04-01) and the Labex "Saclay Plant Science" (ANR-11-IDEX-0003-02). C.R. and M.P. were supported by AutoVirim. We thank the Dormeur Foundation, Vaduz, for providing the AID ELISPOT Reader. We also thank the Agence Nationale de Recherche sur le SIDA et les hepatites virales (ANRS) and Sidaction for fundings. M.P. and L.B. were supported by Sidaction. A.K. and R.J.-M. are ANRS fellows.

\section{Author contributions}

Conceived and design the project: A.M.. Design and performed the experiments: M.P., C.R., L.B., M.G., A.K., G.S., C.P., S.G. R.J-M. E.R. B.M. and B.C.R.. Analysed the data: M.P., C.R., L.B., A.K., M.G., C.P., S.G., B.M., S.G.-D., B.C.R. and A.M.. Contributed reagents/materials/analysis tools: M.F., A.E., S.S. and B.M.. Wrote the paper: M.P., B.C.R. and A.M..

\section{Conflict of interest}

All other authors declare no financial or commercial conflict of interest. 
bioRxiv preprint doi: https://doi.org/10.1101/2021.04.21.440798; this version posted April 22, 2021. The copyright holder for this preprint (which was not certified by peer review) is the author/funder. All rights reserved. No reuse allowed without permission.

\section{References}

Aichinger M, Wu C, Nedjic J, Klein L (2013) Macroautophagy substrates are loaded onto MHC class II of medullary thymic epithelial cells for central tolerance. The Journal of experimental medicine 210: 287-300

Alvaro-Benito M, Morrison E, Abualrous ET, Kuropka B, Freund C (2018) Quantification of HLA-DM-Dependent Major Histocompatibility Complex of Class II Immunopeptidomes by the Peptide Landscape Antigenic Epitope Alignment Utility. Frontiers in immunology 9: 872

Anderson KS, Cresswell P (1994) A role for calnexin (IP90) in the assembly of class II MHC molecules. The EMBO journal 13: 675-682

Arunachalam B, Cresswell P (1995) Molecular requirements for the interaction of class II major histocompatibility complex molecules and invariant chain with calnexin. J Biol Chem 270: 2784-2790

Bakke O, Dobberstein B (1990) MHC class II-associated invariant chain contains a sorting signal for endosomal compartments. Cell 63: 707-716

Bania J, Gatti E, Lelouard H, David A, Cappello F, Weber E, Camosseto V, Pierre P (2003) Human cathepsin S, but not cathepsin L, degrades efficiently MHC class II-associated invariant chain in nonprofessional APCs. Proc Natl Acad Sci U S A 100: 6664-6669

Benaroch P, Yilla M, Raposo G, Ito K, Miwa K, Geuze HJ, Ploegh HL (1995) How MHC class II molecules reach the endocytic pathway. The EMBO journal 14: 37-49

Bijlmakers MJ, Benaroch P, Ploegh HL (1994) Assembly of HLA DR1 molecules translated in vitro: binding of peptide in the endoplasmic reticulum precludes association with invariant chain. The EMBO journal 13: 2699-2707

Bikoff E, Birshtein BK (1986) T cell clones specific for IgG2a of the a allotype: direct evidence for presentation of endogenous antigen. Journal of immunology 137: 28-34

Blanchet FP, Moris A, Nikolic DS, Lehmann M, Cardinaud S, Stalder R, Garcia E, Dinkins C, Leuba F, Wu L et al (2010) Human immunodeficiency virus-1 inhibition of immunoamphisomes in dendritic cells impairs early innate and adaptive immune responses. Immunity 32: 654-669

Busch R, Cloutier I, Sekaly RP, Hammerling GJ (1996) Invariant chain protects class II histocompatibility antigens from binding intact polypeptides in the endoplasmic reticulum. The EMBO journal 15: 418-428

Choi H, Larsen B, Lin ZY, Breitkreutz A, Mellacheruvu D, Fermin D, Qin ZS, Tyers M, Gingras AC, Nesvizhskii AI (2011) SAINT: probabilistic scoring of affinity purification-mass spectrometry data. Nature methods 8: 70-73

Coulon PG, Richetta C, Rouers A, Blanchet FP, Urrutia A, Guerbois M, Piguet V, Theodorou I, Bet A, Schwartz O et al (2016) HIV-Infected Dendritic Cells Present Endogenous MHC Class II-Restricted Antigens to HIVSpecific CD4+ T Cells. Journal of immunology 197: 517-532

Crotzer VL, Blum JS (2008) Cytosol to lysosome transport of intracellular antigens during immune surveillance. Traffic 9: 10-16

Dani A, Chaudhry A, Mukherjee P, Rajagopal D, Bhatia S, George A, Bal V, Rath S, Mayor S (2004) The pathway for $\mathrm{MHCll}$-mediated presentation of endogenous proteins involves peptide transport to the endo-lysosomal compartment. J Cell Sci 117: 4219-4230

De Angelis Rigotti F, De Gassart A, Pforr C, Cano F, N'Guessan P, Combes A, Camossetto V, Lehner PJ, Pierre P, Gatti E (2017) MARCH9-mediated ubiquitination regulates MHC I export from the TGN. Immunology and cell biology 95: 753-764

De Gassart A, Camosseto V, Thibodeau J, Ceppi M, Catalan N, Pierre P, Gatti E (2008) MHC class II stabilization at the surface of human dendritic cells is the result of maturation-dependent MARCH I down-regulation. Proc Natl Acad Sci U S A 105: 3491-3496

Dengjel J, Schoor O, Fischer R, Reich M, Kraus M, Muller M, Kreymborg K, Altenberend F, Brandenburg J, Kalbacher $\mathrm{H}$ et al (2005) Autophagy promotes MHC class II presentation of peptides from intracellular source proteins. Proc Natl Acad Sci U S A 102: 7922-7927

Denzin LK, Cresswell P (1995) HLA-DM induces CLIP dissociation from MHC class II alpha beta dimers and facilitates peptide loading. Cell 82: 155-165

Diedrich G, Bangia N, Pan M, Cresswell P (2001) A role for calnexin in the assembly of the MHC class I loading complex in the endoplasmic reticulum. Journal of immunology 166: 1703-1709

Dorfel D, Appel S, Grunebach F, Weck MM, Muller MR, Heine A, Brossart P (2005) Processing and presentation of HLA class I and II epitopes by dendritic cells after transfection with in vitro-transcribed MUC1 RNA. Blood 105: 3199-3205

Eisenlohr LC, Hackett CJ (1989) Class II major histocompatibility complex-restricted T cells specific for a virion structural protein that do not recognize exogenous influenza virus. Evidence that presentation of labile $T$ 
bioRxiv preprint doi: https://doi.org/10.1101/2021.04.21.440798; this version posted April 22, 2021. The copyright holder for this preprint (which was not certified by peer review) is the author/funder. All rights reserved. No reuse allowed without permission.

cell determinants is favored by endogenous antigen synthesis. The Journal of experimental medicine 169: 921-931

Falk K, Rotzschke O, Stevanovic S, Jung G, Rammensee HG (1991) Allele-specific motifs revealed by sequencing of self-peptides eluted from MHC molecules. Nature 351: 290-296

Fonteneau JF, Brilot F, Munz C, Gannage M (2016) The Tumor Antigen NY-ESO-1 Mediates Direct Recognition of Melanoma Cells by CD4+ T Cells after Intercellular Antigen Transfer. Journal of immunology 196: 64-71

Forgac M (2007) Vacuolar ATPases: rotary proton pumps in physiology and pathophysiology. Nat Rev Mol Cell Biol 8: 917-929

Fu T, Liu J, Wang Y, Xie X, Hu S, Pan L (2018) Mechanistic insights into the interactions of NAP1 with the SKICH domains of NDP52 and TAX1BP1. Proc Natl Acad Sci U S A 115: E11651-e11660

Ghosh M, Di Marco M, Stevanovic S (2019) Identification of MHC Ligands and Establishing MHC Class I Peptide Motifs. Methods in molecular biology 1988: 137-147

Hu S, Wang Y, Gong Y, Liu J, Li Y, Pan L (2018) Mechanistic Insights into Recognitions of Ubiquitin and Myosin VI by Autophagy Receptor TAX1BP1. J Mol Biol 430: 3283-3296

Jacobson S, Sekaly RP, Bellini WJ, Johnson CL, McFarland HF, Long EO (1988) Recognition of intracellular measles virus antigens by HLA class II restricted measles virus-specific cytotoxic T lymphocytes. Ann $N Y$ Acad Sci 540: 352-353

Jagannath C, Lindsey DR, Dhandayuthapani S, Xu Y, Hunter RL, Jr., Eissa NT (2009) Autophagy enhances the efficacy of BCG vaccine by increasing peptide presentation in mouse dendritic cells. Nature medicine 15: 267-276

Jaraquemada D, Marti M, Long EO (1990) An endogenous processing pathway in vaccinia virus-infected cells for presentation of cytoplasmic antigens to class II-restricted T cells. The Journal of experimental medicine 172: 947-954

Jin Y, Sun C, Feng L, Li P, Xiao L, Ren Y, Wang D, Li C, Chen L (2014) Regulation of SIV antigen-specific CD4+ T cellular immunity via autophagosome-mediated MHC II molecule-targeting antigen presentation in mice. PloS one 9: e93143

Johnson DE, Ostrowski P, Jaumouillé V, Grinstein S (2016) The position of lysosomes within the cell determines their luminal pH. J Cell Biol 212: 677-692

Jongsma ML, Berlin I, Wijdeven RH, Janssen L, Janssen GM, Garstka MA, Janssen H, Mensink M, van Veelen PA, Spaapen RM et al (2016) An ER-Associated Pathway Defines Endosomal Architecture for Controlled Cargo Transport. Cell 166: 152-166

Jurtz V, Paul S, Andreatta M, Marcatili P, Peters B, Nielsen M (2017) NetMHCpan-4.0: Improved Peptide-MHC Class I Interaction Predictions Integrating Eluted Ligand and Peptide Binding Affinity Data. Journal of immunology 199: 3360-3368

Käll L, Canterbury JD, Weston J, Noble WS, MacCoss MJ (2007) Semi-supervised learning for peptide identification from shotgun proteomics datasets. Nat Methods 4: 923-925

Kirkin V (2020) History of the Selective Autophagy Research: How Did It Begin and Where Does It Stand Today? J Mol Biol 432: 3-27

Kirkin V, Rogov VV (2019) A Diversity of Selective Autophagy Receptors Determines the Specificity of the Autophagy Pathway. Mol Cell 76: 268-285

Lakkaraju AK, Abrami L, Lemmin T, Blaskovic S, Kunz B, Kihara A, Dal Peraro M, van der Goot FG (2012) Palmitoylated calnexin is a key component of the ribosome-translocon complex. The EMBO journal 31: 1823-1835

Lapaque N, Jahnke M, Trowsdale J, Kelly AP (2009) The HLA-DRalpha chain is modified by polyubiquitination. J Biol Chem 284: 7007-7016

Lee HK, Mattei LM, Steinberg BE, Alberts P, Lee YH, Chervonsky A, Mizushima N, Grinstein S, Iwasaki A (2010) In vivo requirement for Atg5 in antigen presentation by dendritic cells. Immunity 32: 227-239

Leung CS (2015) Endogenous Antigen Presentation of MHC Class II Epitopes through Non-Autophagic Pathways. Frontiers in immunology 6: 464

Lich JD, Elliott JF, Blum JS (2000) Cytoplasmic processing is a prerequisite for presentation of an endogenous antigen by major histocompatibility complex class II proteins. The Journal of experimental medicine 191: 1513-1524

Lin CY, Nozawa T, Minowa-Nozawa A, Toh H, Aikawa C, Nakagawa I (2019) LAMTOR2/LAMTOR1 complex is required for TAX1BP1-mediated xenophagy. Cell Microbiol 21: e12981

Lotteau V, Teyton L, Peleraux A, Nilsson T, Karlsson L, Schmid SL, Quaranta V, Peterson PA (1990) Intracellular transport of class II MHC molecules directed by invariant chain. Nature 348: 600-605 
bioRxiv preprint doi: https://doi.org/10.1101/2021.04.21.440798; this version posted April 22, 2021. The copyright holder for this preprint (which was not certified by peer review) is the author/funder. All rights reserved. No reuse allowed without permission.

Lynes EM, Raturi A, Shenkman M, Ortiz Sandoval C, Yap MC, Wu J, Janowicz A, Myhill N, Benson MD, Campbell $\mathrm{RE}$ et al (2013) Palmitoylation is the switch that assigns calnexin to quality control or ER Ca2+ signaling. $J$ Cell Sci 126: 3893-3903

Malnati MS, Marti M, LaVaute T, Jaraquemada D, Biddison W, DeMars R, Long EO (1992) Processing pathways for presentation of cytosolic antigen to MHC class II-restricted T cells. Nature 357: 702-704

Manoury B, Mazzeo D, Li DN, Billson J, Loak K, Benaroch P, Watts C (2003) Asparagine endopeptidase can initiate the removal of the MHC class II invariant chain chaperone. Immunity 18: 489-498

Marcu A, Bichmann L, Kuchenbecker L, Kowalewski DJ, Freudenmann LK, Backert L, Mühlenbruch L, Szolek A, Lübke M, Wagner P et al (2020) The HLA Ligand Atlas - A resource of natural HLA ligands presented on benign tissues. bioRxiv: 778944

Mellacheruvu D, Wright Z, Couzens AL, Lambert JP, St-Denis NA, Li T, Miteva YV, Hauri S, Sardiu ME, Low TY et al (2013) The CRAPome: a contaminant repository for affinity purification-mass spectrometry data. Nature methods 10: 730-736

Mildenberger J, Johansson I, Sergin I, Kjobli E, Damas JK, Razani B, Flo TH, Bjorkoy G (2017) N-3 PUFAs induce inflammatory tolerance by formation of KEAP1-containing SQSTM1/p62-bodies and activation of NFE2L2. Autophagy 13: 1664-1678

Miller MA, Ganesan AP, Luckashenak N, Mendonca M, Eisenlohr LC (2015) Endogenous antigen processing drives the primary $C D 4+T$ cell response to influenza. Nature medicine 21: 1216-1222

Moris A, Pajot A, Blanchet F, Guivel-Benhassine F, Salcedo M, Schwartz O (2006) Dendritic cells and HIV-specific CD4+ T cells: HIV antigen presentation, T-cell activation, and viral transfer. Blood 108: 1643-1651

Morris P, Shaman J, Attaya M, Amaya M, Goodman S, Bergman C, Monaco JJ, Mellins E (1994) An essential role for HLA-DM in antigen presentation by class II major histocompatibility molecules. Nature 368: 551-554

Morriswood B, Ryzhakov G, Puri C, Arden SD, Roberts R, Dendrou C, Kendrick-Jones J, Buss F (2007) T6BP and NDP52 are myosin VI binding partners with potential roles in cytokine signalling and cell adhesion. J Cell Sci 120: $2574-2585$

Mukherjee P, Dani A, Bhatia S, Singh N, Rudensky AY, George A, Bal V, Mayor S, Rath S (2001) Efficient presentation of both cytosolic and endogenous transmembrane protein antigens on MHC class II is dependent on cytoplasmic proteolysis. Journal of immunology 167: 2632-2641

Muntasell A, Carrascal M, Alvarez I, Serradell L, van Veelen P, Verreck FA, Koning F, Abian J, Jaraquemada D (2004) Dissection of the HLA-DR4 peptide repertoire in endocrine epithelial cells: strong influence of invariant chain and HLA-DM expression on the nature of ligands. Journal of immunology 173: 1085-1093

Muntasell A, Carrascal M, Serradell L, Veelen Pv P, Verreck F, Koning F, Raposo G, Abián J, Jaraquemada D (2002) HLA-DR4 molecules in neuroendocrine epithelial cells associate to a heterogeneous repertoire of cytoplasmic and surface self peptides. Journal of immunology 169: 5052-5060

Myhill N, Lynes EM, Nanji JA, Blagoveshchenskaya AD, Fei H, Carmine Simmen K, Cooper TJ, Thomas G, Simmen $T$ (2008) The subcellular distribution of calnexin is mediated by PACS-2. Mol Biol Cell 19: 2777-2788

Nakagawa T, Roth W, Wong P, Nelson A, Farr A, Deussing J, Villadangos JA, Ploegh H, Peters C, Rudensky AY (1998) Cathepsin L: critical role in li degradation and CD4 T cell selection in the thymus. Science 280: 450453

Neefjes J, Jongsma MML, Berlin I (2017) Stop or Go? Endosome Positioning in the Establishment of Compartment Architecture, Dynamics, and Function. Trends Cell Biol 27: 580-594

Neefjes JJ, Stollorz V, Peters PJ, Geuze HJ, Ploegh HL (1990) The biosynthetic pathway of MHC class II but not class I molecules intersects the endocytic route. Cell 61: 171-183

Nelde A, Kowalewski DJ, Stevanovic S (2019) Purification and Identification of Naturally Presented MHC Class I and II Ligands. Methods in molecular biology 1988: 123-136

Nuchtern JG, Biddison WE, Klausner RD (1990) Class II MHC molecules can use the endogenous pathway of antigen presentation. Nature 343: 74-76

O'Loughlin T, Masters TA, Buss F (2018) The MYO6 interactome reveals adaptor complexes coordinating early endosome and cytoskeletal dynamics. EMBO Rep 19

Paludan C, Schmid D, Landthaler M, Vockerodt M, Kube D, Tuschl T, Munz C (2005) Endogenous MHC class II processing of a viral nuclear antigen after autophagy. Science 307: 593-596

Perez-Riverol Y, Csordas A, Bai J, Bernal-Llinares M, Hewapathirana S, Kundu DJ, Inuganti A, Griss J, Mayer G, Eisenacher $M$ et al (2019) The PRIDE database and related tools and resources in 2019: improving support for quantification data. Nucleic Acids Res 47: D442-d450

Petkova DS, Verlhac P, Rozieres A, Baguet J, Claviere M, Kretz-Remy C, Mahieux R, Viret C, Faure M (2017) Distinct Contributions of Autophagy Receptors in Measles Virus Replication. Viruses 9 
bioRxiv preprint doi: https://doi.org/10.1101/2021.04.21.440798; this version posted April 22, 2021. The copyright holder for this preprint (which was not certified by peer review) is the author/funder. All rights reserved. No reuse allowed without permission.

Pinet V, Vergelli M, Martin R, Bakke O, Long EO (1995) Antigen presentation mediated by recycling of surface HLA-DR molecules. Nature 375: 603-606

Prasad SA, Yewdell JW, Porgador A, Sadasivan B, Cresswell P, Bennink JR (1998) Calnexin expression does not enhance the generation of MHC class I-peptide complexes. Eur J Immunol 28: 907-913

Ramachandra L, Kovats S, Eastman S, Rudensky AY (1996) Variation in HLA-DM expression influences conversion of MHC class II alpha beta:class II-associated invariant chain peptide complexes to mature peptide-bound class II alpha beta dimers in a normal B cell line. Journal of immunology 156: 2196 - 2204

Rammensee H, Bachmann J, Emmerich NP, Bachor OA, Stevanovic S (1999) SYFPEITHI: database for MHC ligands and peptide motifs. Immunogenetics 50: 213-219

Randow F, Youle RJ (2014) Self and nonself: how autophagy targets mitochondria and bacteria. Cell Host Microbe 15: 403-411

Reith W, LeibundGut-Landmann S, Waldburger JM (2005) Regulation of MHC class II gene expression by the class II transactivator. Nature reviews Immunology 5: 793-806

Reynisson B, Barra C, Kaabinejadian S, Hildebrand WH, Peters B, Nielsen M (2020) Improved Prediction of MHC II Antigen Presentation through Integration and Motif Deconvolution of Mass Spectrometry MHC Eluted Ligand Data. J Proteome Res 19: 2304-2315

Richter B, Sliter DA, Herhaus L, Stolz A, Wang C, Beli P, Zaffagnini G, Wild P, Martens S, Wagner SA et al (2016) Phosphorylation of OPTN by TBK1 enhances its binding to Ub chains and promotes selective autophagy of damaged mitochondria. Proc Natl Acad Sci U S A 113: 4039-4044

Riese RJ, Wolf PR, Bromme D, Natkin LR, Villadangos JA, Ploegh HL, Chapman HA (1996) Essential role for cathepsin S in MHC class II-associated invariant chain processing and peptide loading. Immunity 4: 357-366

Roche PA, Cresswell P (1991) Proteolysis of the class II-associated invariant chain generates a peptide binding site in intracellular HLA-DR molecules. Proc Natl Acad Sci U S A 88: 3150-3154

Roche PA, Furuta K (2015) The ins and outs of MHC class II-mediated antigen processing and presentation. Nature reviews Immunology 15: 203-216

Roche PA, Marks MS, Cresswell P (1991) Formation of a nine-subunit complex by HLA class II glycoproteins and the invariant chain. Nature 354: 392-394

Romagnoli P, Germain RN (1995) Inhibition of invariant chain (li)-calnexin interaction results in enhanced degradation of li but does not prevent the assembly of alpha beta li complexes. The Journal of experimental medicine 182: 2027-2036

Rudensky A, Preston-Hurlburt P, Hong SC, Barlow A, Janeway CA, Jr. (1991) Sequence analysis of peptides bound to MHC class II molecules. Nature 353: 622-627

Rudensky AY, Yurin VL (1989) Immunoglobulin-specific T-B cell interaction. I. Presentation of self immunoglobulin determinants by B lymphocytes. Eur J Immunol 19: 1677-1683

Sahlender DA, Roberts RC, Arden SD, Spudich G, Taylor MJ, Luzio JP, Kendrick-Jones J, Buss F (2005) Optineurin links myosin VI to the Golgi complex and is involved in Golgi organization and exocytosis. The Journal of cell biology 169: 285-295

Sanderson F, Kleijmeer MJ, Kelly A, Verwoerd D, Tulp A, Neefjes JJ, Geuze HJ, Trowsdale J (1994) Accumulation of HLA-DM, a regulator of antigen presentation, in MHC class II compartments. Science 266: 1566-1569

Schmid D, Pypaert M, Munz C (2007) Antigen-loading compartments for major histocompatibility complex class II molecules continuously receive input from autophagosomes. Immunity 26: 79-92

Schröder B (2016) The multifaceted roles of the invariant chain CD74--More than just a chaperone. Biochim Biophys Acta 1863: 1269-1281

Schuster C, Gerold KD, Schober K, Probst L, Boerner K, Kim MJ, Ruckdeschel A, Serwold T, Kissler S (2015) The Autoimmunity-Associated Gene CLEC16A Modulates Thymic Epithelial Cell Autophagy and Alters T Cell Selection. Immunity 42: 942-952

Scott JE, Dawson JR (1995) MHC class I expression and transport in a calnexin-deficient cell line. Journal of immunology 155: 143-148

Sekaly RP, Jacobson S, Richert JR, Tonnelle C, McFarland HF, Long EO (1988) Antigen presentation to HLA class II-restricted measles virus-specific T-cell clones can occur in the absence of the invariant chain. Proceedings of the National Academy of Sciences of the United States of America 85: 1209-1212

Shembade N, Harhaj NS, Parvatiyar K, Copeland NG, Jenkins NA, Matesic LE, Harhaj EW (2008) The E3 ligase Itch negatively regulates inflammatory signaling pathways by controlling the function of the ubiquitinediting enzyme A20. Nat Immunol 9: 254-262

Shembade N, Ma A, Harhaj EW (2010) Inhibition of NF-kappaB signaling by A20 through disruption of ubiquitin enzyme complexes. Science 327: 1135-1139 
bioRxiv preprint doi: https://doi.org/10.1101/2021.04.21.440798; this version posted April 22, 2021. The copyright holder for this preprint (which was not certified by peer review) is the author/funder. All rights reserved. No reuse allowed without permission.

Shi GP, Bryant RA, Riese R, Verhelst S, Driessen C, Li Z, Bromme D, Ploegh HL, Chapman HA (2000) Role for cathepsin $\mathrm{F}$ in invariant chain processing and major histocompatibility complex class II peptide loading by macrophages. The Journal of experimental medicine 191: 1177-1186

Shin JS, Ebersold M, Pypaert M, Delamarre L, Hartley A, Mellman I (2006) Surface expression of MHC class II in dendritic cells is controlled by regulated ubiquitination. Nature 444: 115-118

Sinnathamby G, Eisenlohr LC (2003) Presentation by recycling MHC class II molecules of an influenza hemagglutinin-derived epitope that is revealed in the early endosome by acidification. Journal of immunology 170: 3504-3513

Tewari MK, Sinnathamby G, Rajagopal D, Eisenlohr LC (2005) A cytosolic pathway for MHC class II-restricted antigen processing that is proteasome and TAP dependent. Nature immunology 6: 287-294

Thibodeau J, Moulefera MA, Balthazard R (2019) On the structure-function of MHC class II molecules and how single amino acid polymorphisms could alter intracellular trafficking. Hum Immunol 80: 15-31

Thiele F, Tao S, Zhang Y, Muschaweckh A, Zollmann T, Protzer U, Abele R, Drexler I (2015) Modified vaccinia virus Ankara-infected dendritic cells present CD4+ T-cell epitopes by endogenous major histocompatibility complex class II presentation pathways. Journal of virology 89: 2698-2709

Thurston TL, Ryzhakov G, Bloor S, von Muhlinen N, Randow F (2009) The TBK1 adaptor and autophagy receptor NDP52 restricts the proliferation of ubiquitin-coated bacteria. Nat Immunol 10: 1215-1221

Tsuji T, Matsuzaki J, Caballero OL, Jungbluth AA, Ritter G, Odunsi K, Old L, Gnjatic S (2012) Heat shock protein 90-mediated peptide-selective presentation of cytosolic tumor antigen for direct recognition of tumors by CD4(+) T cells. Journal of immunology 188: 3851-3858

Tumbarello DA, Manna PT, Allen M, Bycroft M, Arden SD, Kendrick-Jones J, Buss F (2015) The Autophagy Receptor TAX1BP1 and the Molecular Motor Myosin VI Are Required for Clearance of Salmonella Typhimurium by Autophagy. PLoS pathogens 11: e1005174

Tumbarello DA, Waxse BJ, Arden SD, Bright NA, Kendrick-Jones J, Buss F (2012) Autophagy receptors link myosin $\mathrm{VI}$ to autophagosomes to mediate Tom1-dependent autophagosome maturation and fusion with the lysosome. Nat Cell Biol 14: 1024-1035

Tyanova S, Temu T, Sinitcyn P, Carlson A, Hein MY, Geiger T, Mann M, Cox J (2016) The Perseus computational platform for comprehensive analysis of (prote)omics data. Nat Methods 13: 731-740

Unanue ER, Turk V, Neefjes J (2016) Variations in MHC Class II Antigen Processing and Presentation in Health and Disease. Annu Rev Immunol 34: 265-297

Vassilakos A, Cohen-Doyle MF, Peterson PA, Jackson MR, Williams DB (1996) The molecular chaperone calnexin facilitates folding and assembly of class I histocompatibility molecules. The EMBO journal 15: 1495-1506

Veerappan Ganesan AP, Eisenlohr LC (2017) The elucidation of non-classical MHC class II antigen processing through the study of viral antigens. Curr Opin Virol 22: 71-76

Verlhac P, Gregoire IP, Azocar O, Petkova DS, Baguet J, Viret C, Faure M (2015) Autophagy receptor NDP52 regulates pathogen-containing autophagosome maturation. Cell host \& microbe 17: 515-525

Walseng E, Furuta K, Bosch B, Weih KA, Matsuki Y, Bakke O, Ishido S, Roche PA (2010) Ubiquitination regulates MHC class II-peptide complex retention and degradation in dendritic cells. Proc Natl Acad Sci U S A 107: 20465-20470

Watts C (2004) The exogenous pathway for antigen presentation on major histocompatibility complex class II and CD1 molecules. Nature immunology 5: 685-692

Weil R, Laplantine E, Curic S, Génin P (2018) Role of Optineurin in the Mitochondrial Dysfunction: Potential Implications in Neurodegenerative Diseases and Cancer. Frontiers in immunology 9: 1243

Weiss S, Bogen B (1989) B-lymphoma cells process and present their endogenous immunoglobulin to major histocompatibility complex-restricted T cells. Proc Natl Acad Sci U S A 86: 282-286

Wijdeven RH, van Luijn MM, Wierenga-Wolf AF, Akkermans JJ, van den Elsen PJ, Hintzen RQ, Neefjes J (2018) Chemical and genetic control of IFNgamma-induced MHCII expression. EMBO Rep 19

Wild P, Farhan H, McEwan DG, Wagner S, Rogov VV, Brady NR, Richter B, Korac J, Waidmann O, Choudhary C et al (2011) Phosphorylation of the autophagy receptor optineurin restricts Salmonella growth. Science 333: 228-233

Zhou D, Li P, Lin Y, Lott JM, Hislop AD, Canaday DH, Brutkiewicz RR, Blum JS (2005) Lamp-2a facilitates MHC class II presentation of cytoplasmic antigens. Immunity 22: 571-581 


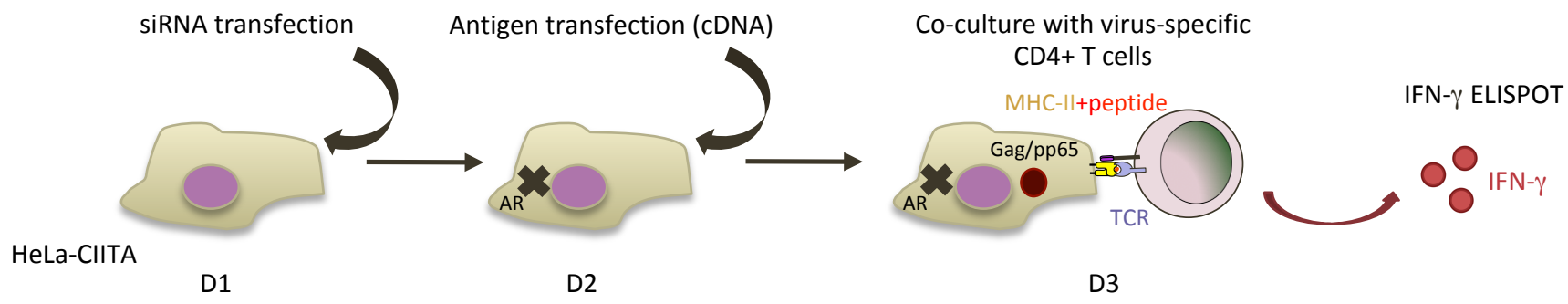

B

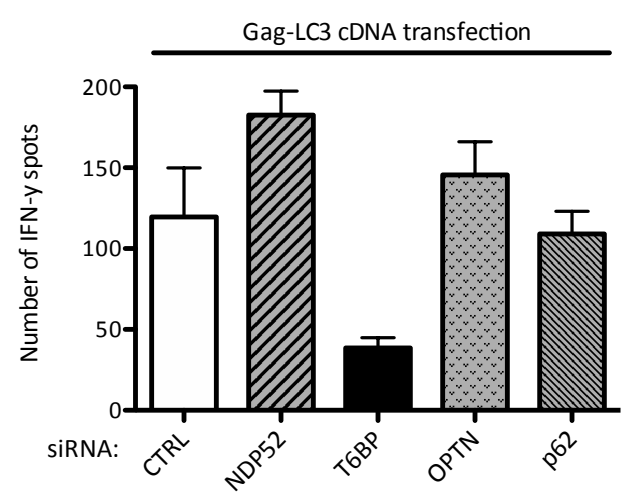

cDNA

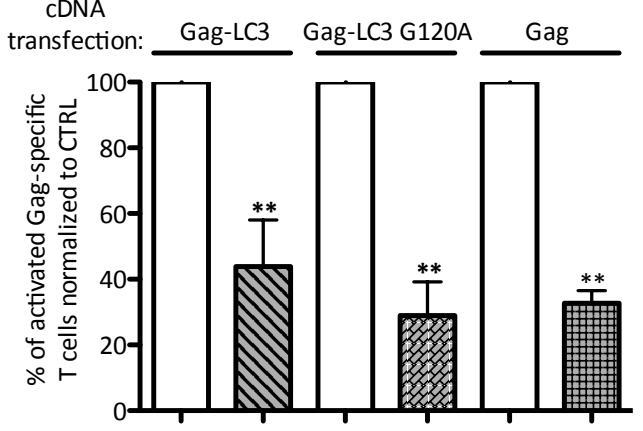

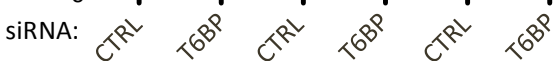

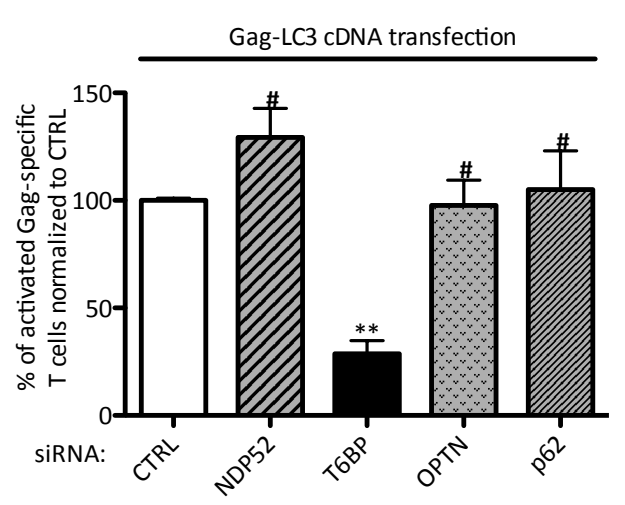

C

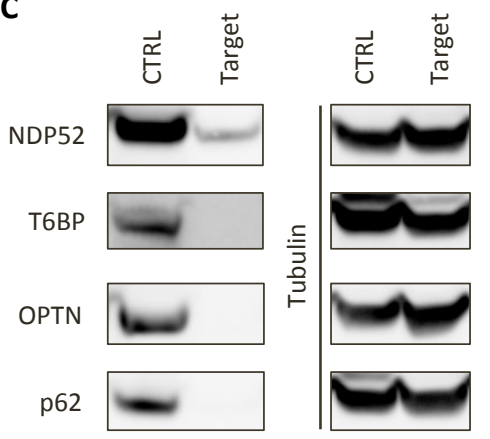

$\mathbf{E}$

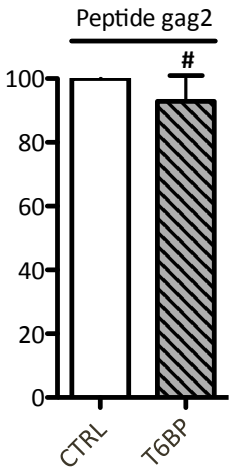

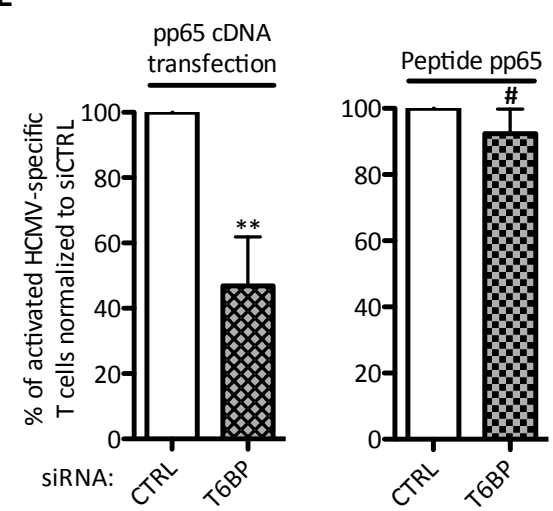

Figure 1. T6BP silencing influences endogenous viral $\mathrm{Ag}$ presentation and $\mathrm{CD} 4^{+} \mathrm{T}$ cell activation. (A) Schematic representation of the experiment. Hela-CIITA cells were transfected with siRNAs and 24h later with plasmids encoding the antigens. 24h post-DNA transfection, Hela-CIITA cells were co-cultured with antigen-specific CD4+ T cells and T cell activation assessed. AR: Autophagy Receptor; D: day; TCR: T-cell receptor (B) Monitoring of Gag-specific T cell activation using IFN $\gamma$-ELISPOT. HeLa-CIITA cells were treated with the indicated siRNA targeting ARs and transfected with a plasmid encoding Gag-LC3. HeLa-CIITA cells were then co-cultured with Gag-specific T cells. Left panel, a representative experiment is shown. Right panel, three independent experiments are combined and presented as the mean percentage (+/-SD) of activated cells producing IFN $\gamma$ normalized to CTRL conditions. (C) $48 \mathrm{~h}$ post-transfection of HeLaCIITA cells with siRNAs targeting NDP52, T6BP, OPTN, and p62, AR expression was analysed using Western Blot. Tubulin was used as control housekeeping gene expression. The results are representative of at least 3 independent experiments and correspond to AR expression levels of the experiment in Figure 1B, left panel. (D) Left panel, as in Figure 1B, but using CDNA encoding Gag-LC3, Gag-LC3 ${ }_{\mathrm{G} 120 \mathrm{~A}}$, or Gag. Right panel, influence of T6BP silencing on peptide presentation by Hela-CIITA cells. The cognate peptide was added exogenously (gag2, $0,5 \mu \mathrm{g} / \mathrm{mL}$ ) on siRNA-treated cells $\left(2 \mathrm{~h}, 37^{\circ} \mathrm{C}\right)$, washed and T cell activation monitored using IFN $\gamma$-ELISPOT. Results are presented as the mean percentage (+/- SD) of activated cells producing IFN $\gamma$ normalized to CTRL conditions from at least three independent experiments. (E) As in (D) but using CDNA encoding HCMV pp65 antigen (left panel) or pp65 peptide $(0,5 \mu \mathrm{g} / \mathrm{mL}$; right panel) and a pp65-specific $\mathrm{CD}^{+}{ }^{+} \mathrm{T}$ cell line. Results of three independent experiments are represented. For all ELISPOT experiments, the background secretions of IFN $\gamma$ by $\mathrm{CD}^{+} \mathrm{T}$ cells co-cultured with mock-treated HeLa-CIITA cells were used as negative controls and subtracted. CTRL: control. Wilcoxon's tests; ${ }^{* *} p<0.01 ;{ }^{*} p<0.05 ; \# p>0.05$. 
A

Mock1

Mock2

SiCTRL

siT6BP

Nb of peptides: $\quad$ Exclusive ${ }^{\text {Shared }}{ }^{\text {Exclusive }} 1323$

\begin{tabular}{ccc} 
Exclusive Shared & \multicolumn{2}{c}{ Exclusive } \\
1349 & 1914 & 2198
\end{tabular}
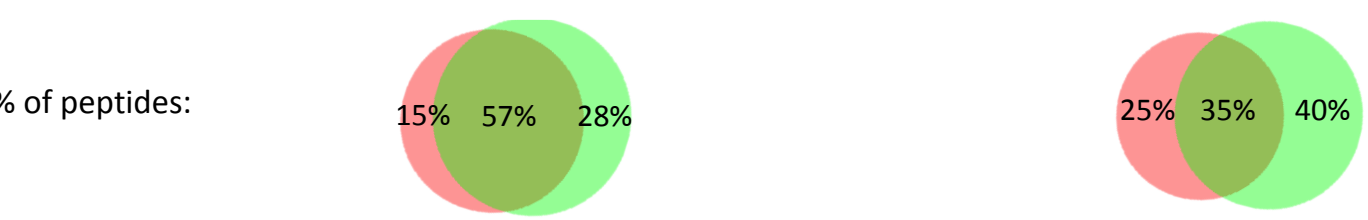

B
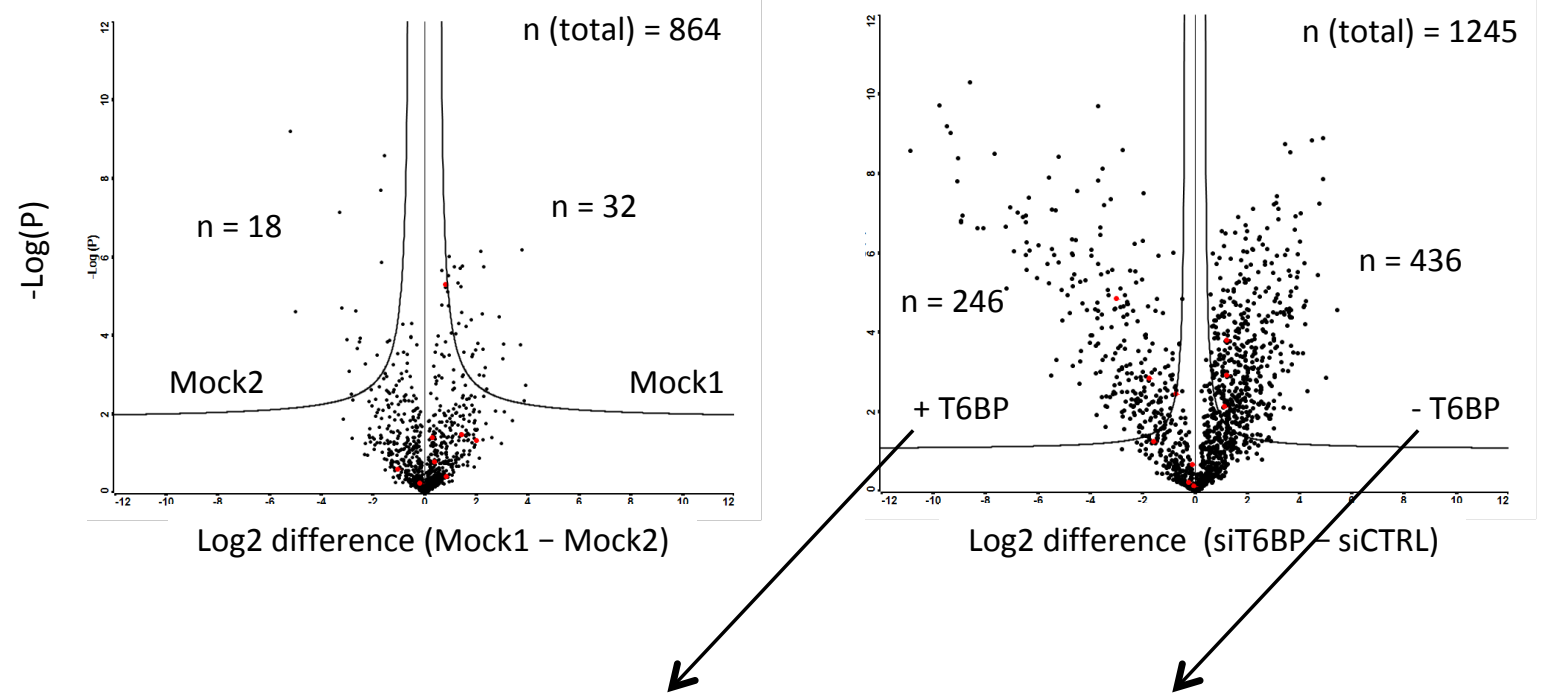

C
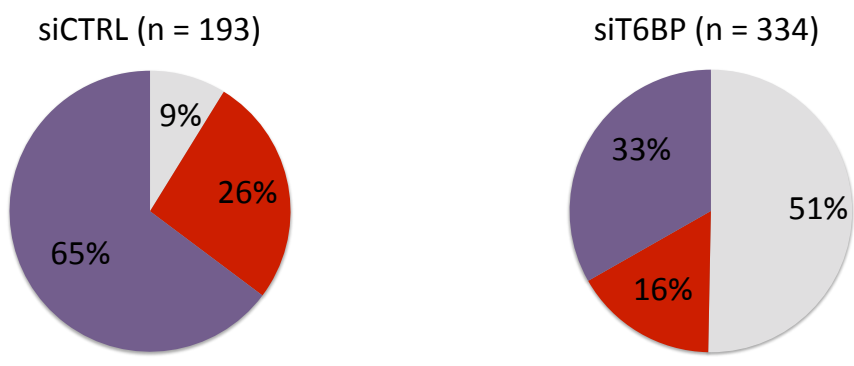

Binding scores:

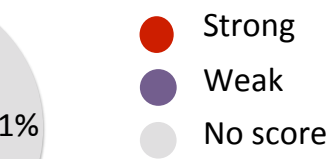

Figure 2: T6BP silencing alters the immunopeptidome of MHC-II molecules. (A) Left panel, mock-treated HeLa-CIITA cells were split and culture for $48 \mathrm{~h}$ (giving rise to Mock1 and Mock2), then cells were lysed, MHC-II molecules were immunoprecipitated using TÜ39 antibody and the peptide-ligands sequenced using mass-spectrometry (LC-MS/MS). (A) Right panel, HeLa-CIITA cells were transfected with siCTRL and siT6BP siRNA and were treated as in the left panel. The number and the percentage among sequenced peptides (Venn diagrams) of exclusive or shared peptides for each conditions are presented. Quantitative (B) and qualitative (C) assessment of T6BP influence on the immunopeptidome. Data from (A) were submitted to PLAtEAU algorithm to allow identification and label-free quantification of shared consensus core epitopes. (B) Volcano plots showing the $\log _{2}$ fold-change of core epitope intensity between siCTRL and siT6BP-treated cells (right panel) and Mock1 and Mock2 (left panel). For peptides exclusive to one or the other conditions, a background score was imputed to allow log2 fold-change presentation. An FDR of 0.01 and an SO of 0.2 as correction factor for differences in the means were used. The resulting interval of confidence are highlighted by solid lines shown in each graph. The total number ( $n$ ) of core epitopes and the number of epitopes with significant fold-change are indicated. (C) Relative binding affinities, presented as pie charts, of exclusive core epitopes identified by PLAtEAU in siCTRL (left) and siT6BP (right) conditions (number of epitopes are indicated in brackets). NetMHCllpan was used to predict the relative affinities to HLA-DR $\beta 1^{*} 0102$ expressed by HeLaCIITA cells. The results are presented as stated from NetMHCllpan analysis as Strong (for strong binders), Weak (for weak binders), and No score (for epitopes for which no binding score could be determined). Except for the Mock conditions, one representative experiment is shown out of two biological replicates. For each experiment, 5 technical replicates per sample were analysed. $\mathrm{Nb}$ : number; \%: percentage. 

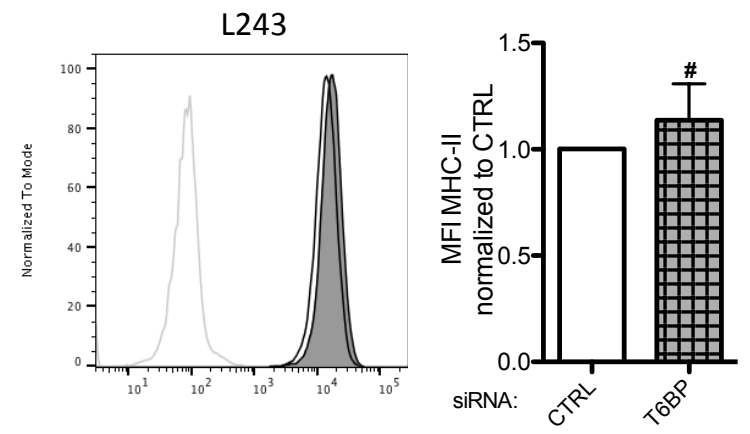

B

C
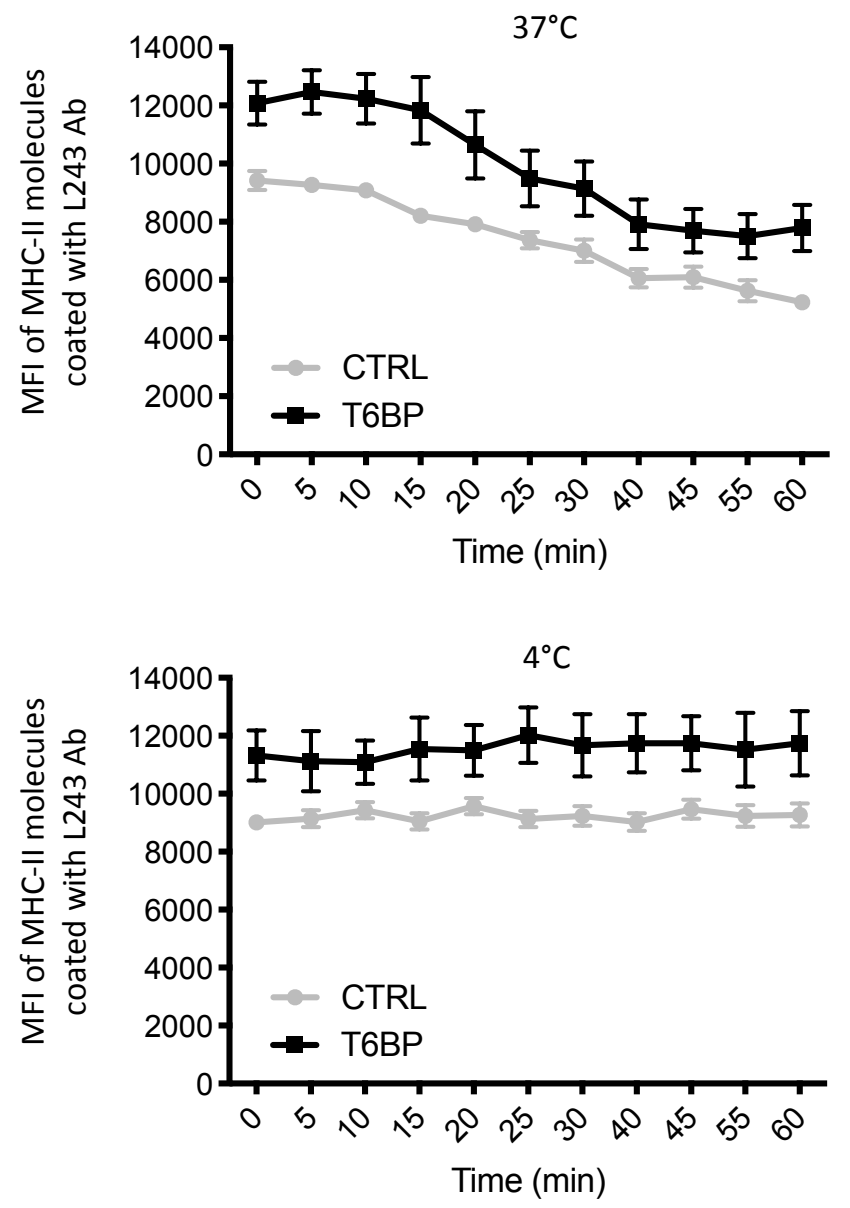
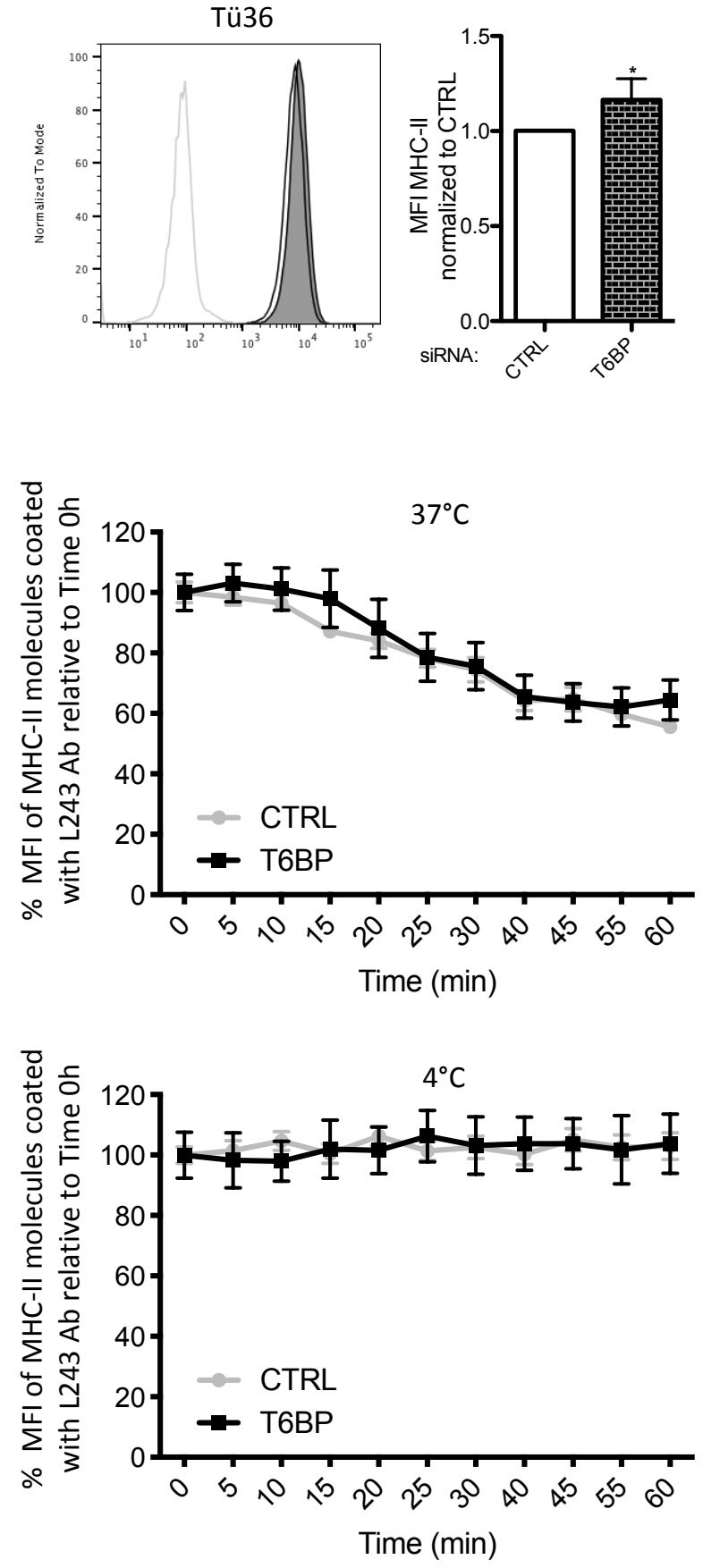

Figure 3. T6BP silencing mildly influences the cell-surface expression levels but has no impact on the internalization kinetics of MHC-II molecules. (A) Cell-surface expression of MHC-II molecules was assessed using flow cytometry. HeLaCIITA cells were transfected with siCTRL and siT6BP. 48h post-treatment, mature and mature/immature HLA-DR molecules were detected using L243 (left panels) and Tü36 antibodies (right panels), respectively. Left, MFI of one representative experiment is presented as histogram. Right, at least five independent experiments were combined and presented as the means (+/- SD) of mean fluorescent intensity (MFI) standardized to the control conditions. Light grey lines : isotype negative controls; black lines and filled grey lines: anti-MHC-Il stainings of siCTRL- and siT6BP-treated cells, respectively (B) and (C) HeLa-CIITA cells were transfected with control and T6BP-silencing siRNA. 48h posttreatment, mature HLA-DR molecules were stained at $4^{\circ} \mathrm{C}$ using L243 antibody. Cells were then incubated at $37^{\circ} \mathrm{C}$ (B) or at $4^{\circ} \mathrm{C}$ (C) as control. At indicated time-points, cells were stained with a fluorescently-labelled secondary antibody at $4^{\circ} \mathrm{C}$. Results are represented as MFI of MHC-II molecules stained with the L243 antibody (Ab) remaining at the cell surface (B and C, left panels), or as percentage (\%) of MFI relative to time $0 \mathrm{~h}(100 \%)$ (B and C, right panels). Results are representative of three independent experiments. CTRL: control. Mann-Whitney's tests; ${ }^{*} p<0.05 ; \# p>0.05$. 

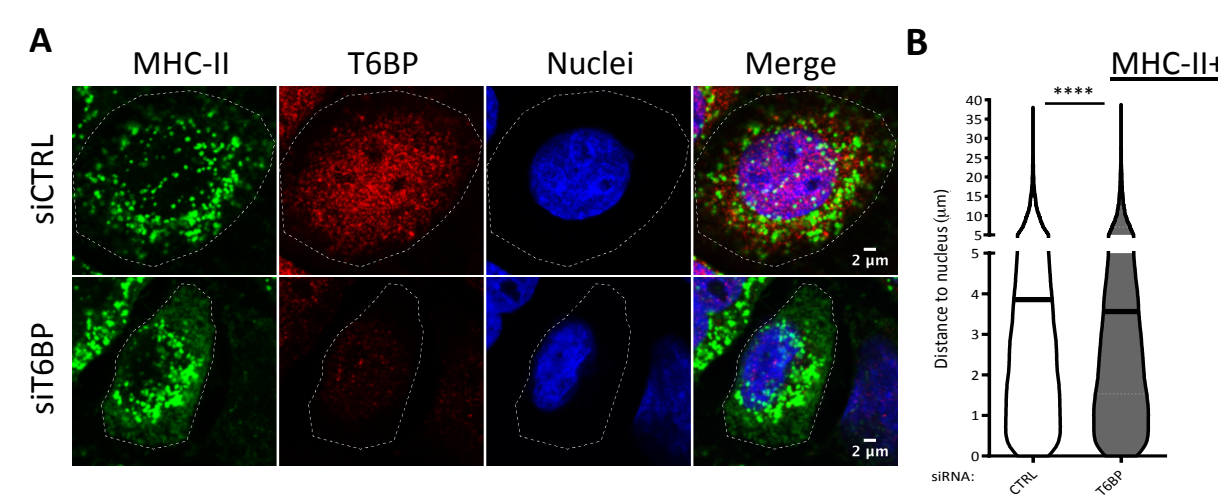

C LAMP-1

T6BP

Nuclei

D
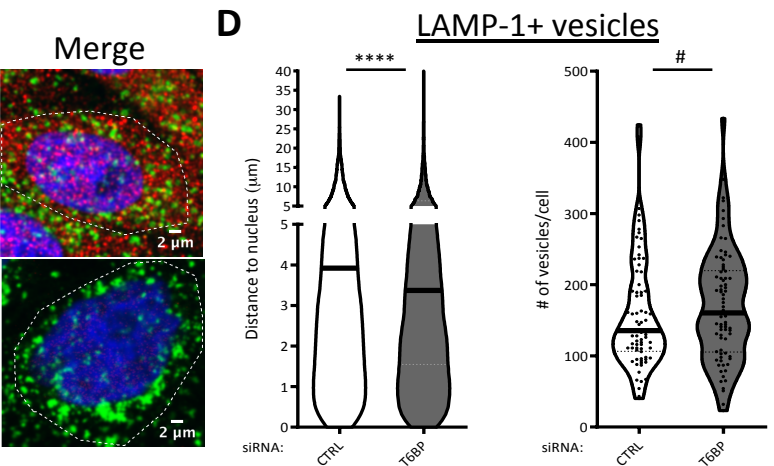

F

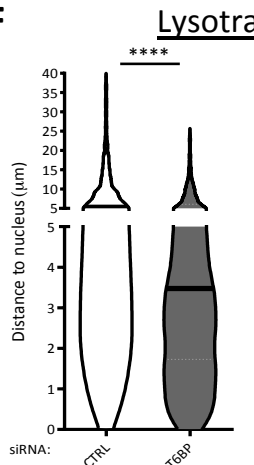

Merge

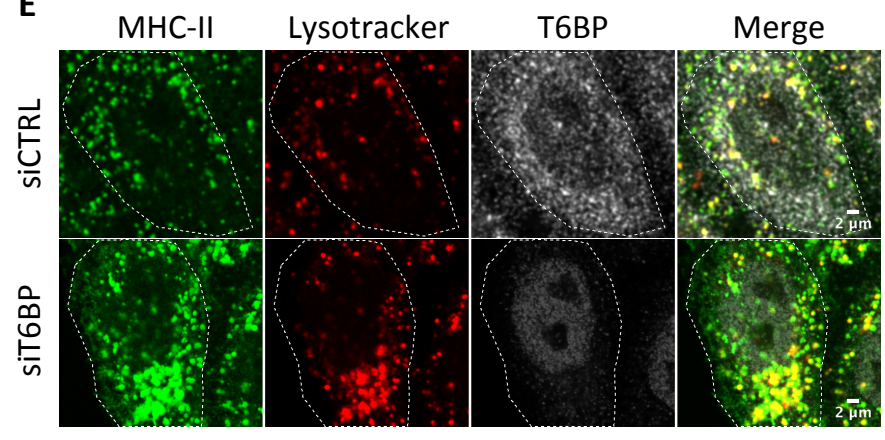

H

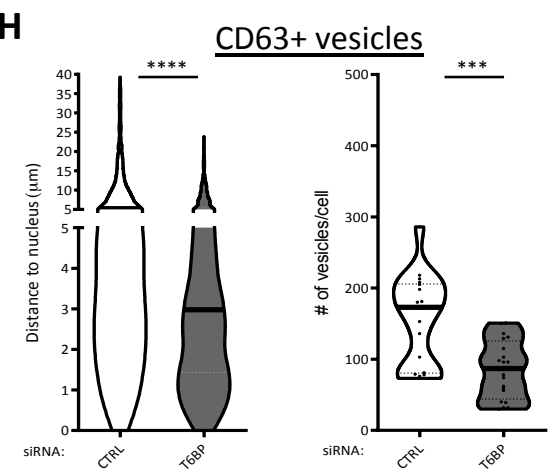

Co-localization

MHC-II : Lysotracker

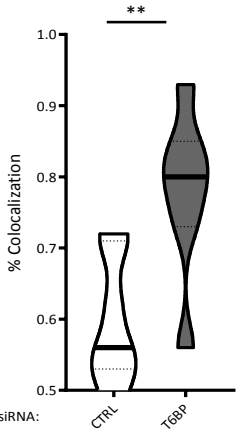

Co-localization

G

T6BP

Merge

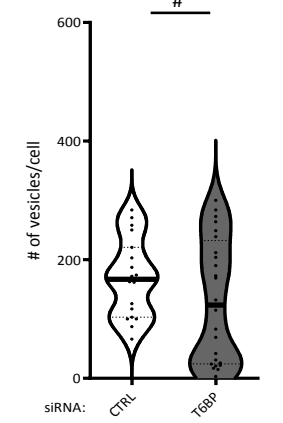

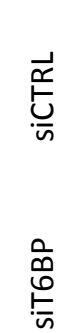

CD63

MHC-II

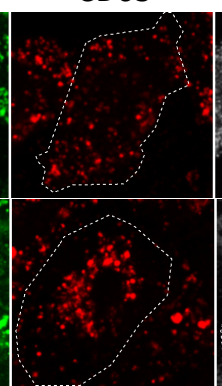

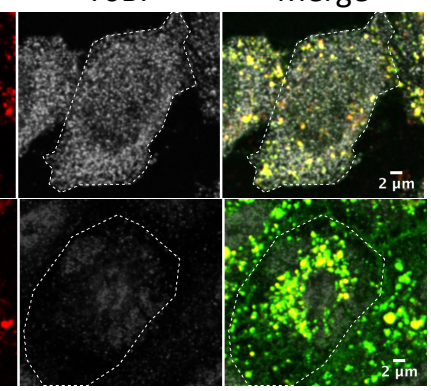

....

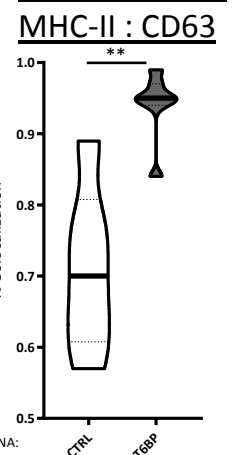

Figure 4. T6BP silencing leads to perinuclear relocalization of the MIIC. (A) MHC-II and T6BP expressions were assessed using confocal microscopy. HeLa-CIITA cells were transfected with control and T6BP-silencing siRNA. 48h post-treatment, MHC-II and T6BP were detected using L243 and anti-T6BP antibodies, respectively, and revealed with species specific secondary antibodies. Nuclei were stained using DAPI. (B) Quantitative analysis using in-house ImageJ script displaying distance of each MHC-II+ vesicles to the nucleus and number of vesicles per cell. At least 20,000 vesicles from 160 cells corresponding to 5 independent experiments were analyzed. Right panel, quantification in the SiCTRL cells of the potential colocalization between MHC- $\mathrm{II}^{+}$and T6BP+ dots using Pearson's coefficient where the dotted lines (at 0.5 ) indicate the limit under which no significant co-localization is measured (number of cells $=54$ ). (C) As in A, T6BP and LAMP-1 expressions were analyzed. (D) The localization of LAMP- $1^{+}$vesicles and the number of vesicles per cell were quantified as in $B$. At least 2000 vesicles from 20 cells corresponding to 2 independent experiments were analyzed. (E) As in A, adding Lysotracker staining. (F) As in B, quantitative analysis of Lysotracker ${ }^{+}$vesicles: localization to the nucleus and number of vesicles per cell. Colocalization of Lysotracker ${ }^{+}$vesicles with $\mathrm{MHC}-\mathrm{II}^{+}$puncta was analyzed using JACoP plugin (scales start at 0.5 above which the \% of co-localization is considered significant), number of vesicles > 2000 from at least 2 independent experiments were analyzed corresponding to 20 cells. (G) As in E, CD63 and MHC-II expressions were assessed. (H) Quantitative analysis as represented in F. At least 2000 vesicles from 20 cells corresponding to 2 independent experiments were analyzed. In graphs representing the number of vesicles per cells, each dot displayed corresponds to a single cell. Scale bars, $2 \mu \mathrm{m}$. CTRL: control. Mann-Whitney's tests; ${ }^{*} p<0.05 ;{ }^{*} p<0.002 ;{ }^{* *} p<0.0003 ;{ }^{* * *} \mathrm{p}<0.0001 ; \# p>0.05$. 


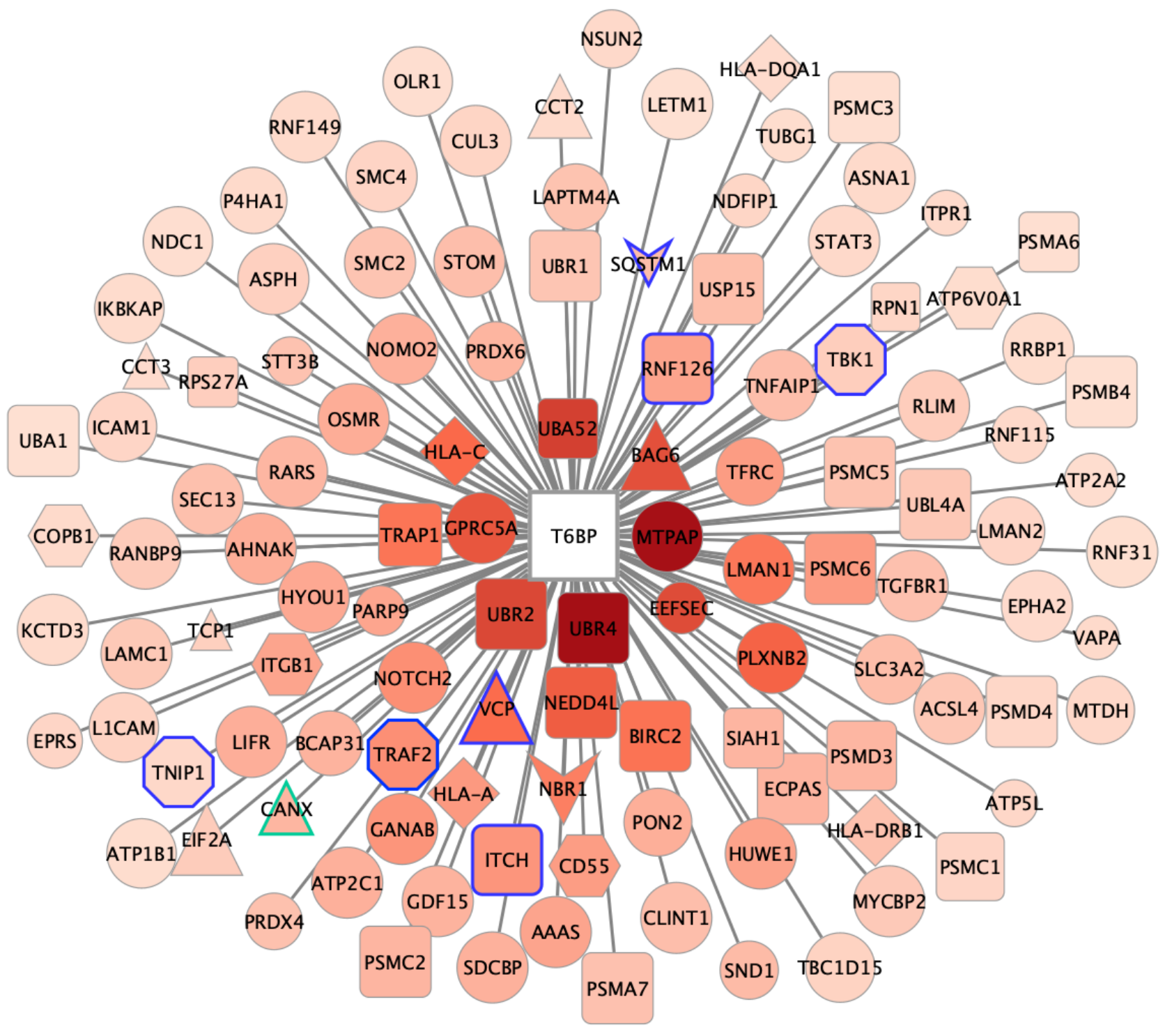

\section{Main pathways}

$\diamond$ Antigen presentation

$Y$ Autophagy

$\triangle$ Endocytosis

NFkB signaling

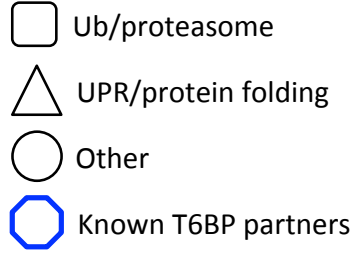

Selecting criteria

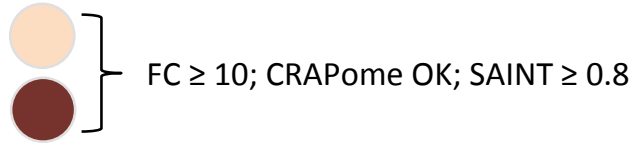

$\triangle$ CANX: Calnexin

Figure 6. T6BP interactome reveals novel binding partners. Diagram of the T6BP protein interaction network identified by immunoprecipitation followed by LC-MS/MS and represented using Cytoscape. T6BP (white) coupled to GFP was immunoprecipitated using anti-GFP camel antibodies (GFP-Trap Chromotek). GFP alone was used as control. Proteins were considered as relevant partners based on the following criteria: at least 2 peptides were identified by LC-MS/MS, the fold-change (FC) to the GFP control condition $\geq 10$, SAINT probability threshold $\geq 0,8$. For data analysis the Resource for Evaluation of Protein Interaction Networks (REPRINT) and its contaminant repository (CRAPome V2.0) were used. The edge's length is inversely proportional to the FC score (short edge $=$ high FC) and the node's color intensity is directly proportional to the FC score (the more intense the higher the FC). The size of the node is directly proportional to the SAINT score (lower confidence $=$ smaller node). Blue border indicates previously described partners of T6BP. The shape of the node highlights the functional pathway in which the candidate protein is enriched based on Ingenuity. Green border indicates Calnexin = CANX. 
A

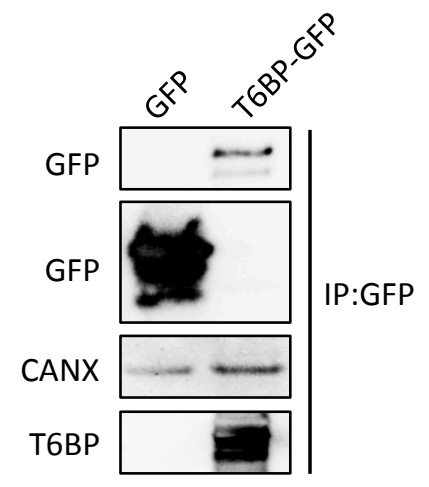

D

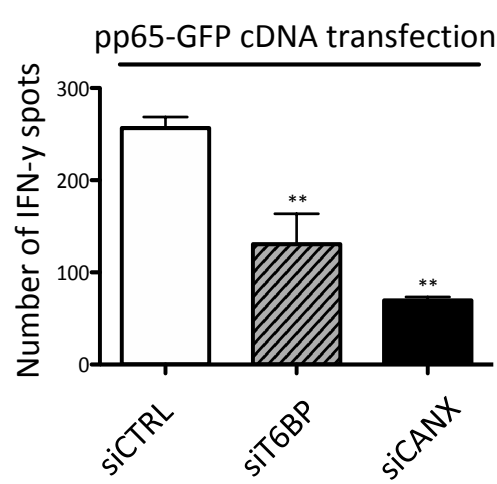

B

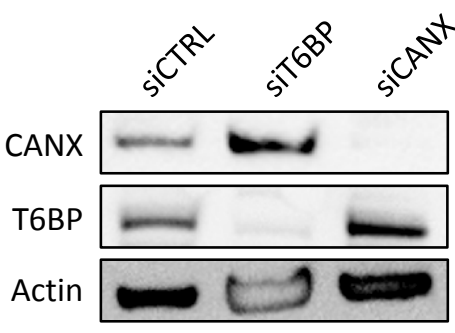

C

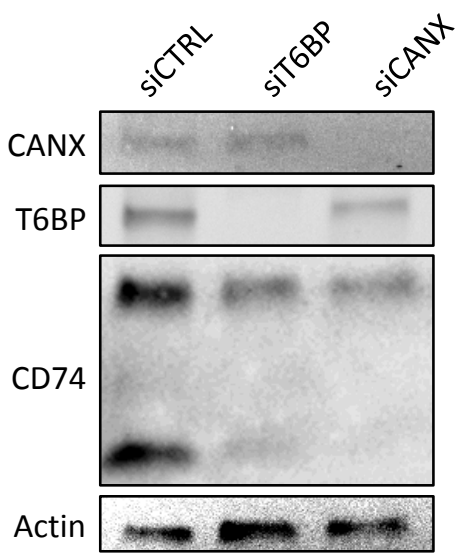

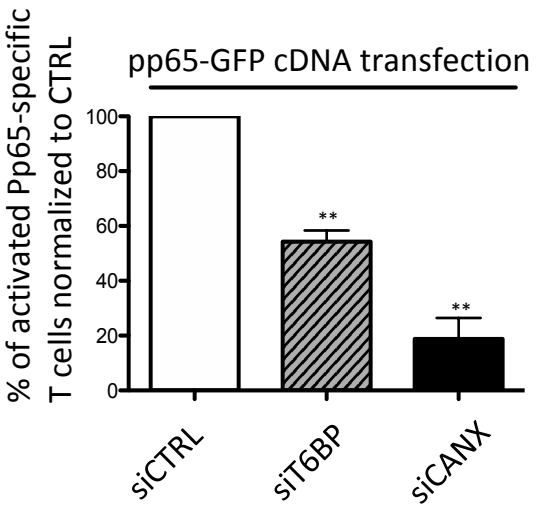

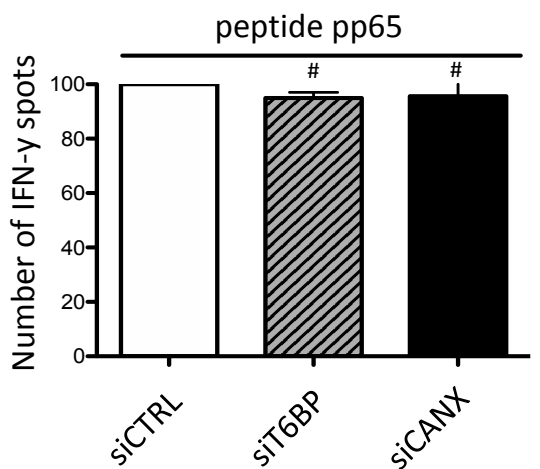

Figure 7. Calnexin silencing induces CD74 degradation and dampers MHC-II-restricted presentation to CD4 ${ }^{+}$cells. (A) GFP nanobody immunoprecipitates from HeLa-CIITA cells transfected with GFP and T6BP-GFP. 48h posttransfection, samples were analysed by Western blot with the indicated antibodies. (B) Silencing of T6BP expression does not influence calnexin (CANX) expression levels. HeLa-CIITA cells transfected with the indicated siRNAs and samples analysed, $48 \mathrm{~h}$ post transfection, by Western blot with the indicated antibodies. The ratios of the target protein expression to Actin expression were quantify using ImageJ and are presented. For the quantification of T6BP, since the signal is saturated, the band was filled. (C) Silencing of CANX expression reduces the levels of CD74 expression. As in (B) using the indicated antibody for western blot analysis. The western blot results are representative of at least 3 independent experiments (D) CANX silencing dampers MHC-II-restricted presentation to $\mathrm{CD}^{+}{ }^{+} \mathrm{T}$ cells. Monitoring of pp65-specific T cell activation using IFN $\gamma$-ELISPOT. HeLa-CIITA cells were treated with the indicated siRNAs and transfected with a plasmid encoding pp65 HCMV antigen fused to GFP. HeLa-CIITA cells were then co-cultured with pp65-specific T cells. Left panel, a representative experiment is shown. The siRNA silencing results of the cells used in this panel are presented in Panel B. Right panel, three independent experiments are combined and presented as the mean percentage (+/-SD) of activated cells producing IFN $\gamma$ normalized to CTRL conditions. The background secretions of IFN $\gamma$ by $\mathrm{CD}_{4}^{+} \mathrm{T}$ cells co-cultured with mock-treated HeLa-CIITA cells were used as negative controls and subtracted. CTRL: control. Wilcoxon's tests; ${ }^{* *} p<0.01 ;{ }^{*} p<0.05 ; \# p>0.05$. 